\title{
Biomass and bioenergy supply from Mozambique
}

\author{
Bothwell Batidzirai, André P.C. Faaij and Edward Smeets \\ Copernicus Institute, Utrecht University, Department of Science, Technology and Society \\ Heidelberglaan 2, 3584 CS, Utrecht, the Netherlands \\ E-mail (Faaij): A.Faaij@chem.uu.nl
}

\begin{abstract}
Modern biofuels are a promising long-term renewable energy source which has potential to address both environmental impacts and security concerns posed by current dependence on fossil fuels. Energy crops represent the largest potential source of bioenergy feedstocks but land availability is a crucial precondition for this. On the basis of global bioenergy production potential assessments, Mozambique was identified as one of the promising biomass production regions in tropical Africa. It has capacity to produce up to $6.7 \mathrm{EJ}$ (all energy values for fuels in $\mathrm{HHV}$ ) of bioenergy annually with moderate introduction of agricultural technology and using strict sustainability criteria (i.e., protecting forests and meeting growing food demand). Essential for realising this potential is rationalisation in agriculture and livestock-raising, and potential increases of up to 7 times current productivities can be achieved with moderate technology introduction. Efficient logistics are also essential to ensure competitive biomass supply to the international market. Using six regions of Mozambique as potential sites of biomass production, this study analysed and compared the cost and energy use of supplying pellets, pyrolysis oil and Fischer-Tropsch (FT) fuels to the international market.

Production costs of eucalyptus vary from 0.6 to 1.15 Euro/GJ for biomass productivities ranging between 7 and $25 t_{\mathrm{dm}} / \mathrm{ha} / \mathrm{yr}$ for arid to productive regions. Using Rotterdam harbour as an international destination for biofuels, the lowest delivered biofuel costs are 2.6 Euro/GJ for pellets, 3.2 Euro/GJ for pyrolysis oil and 6.8 Euro/GJ for FT fuels produced via circulating fluidised bed gasification (all originating from Sofala province). Lower costs are achieved for early conversion to pellets and pyrolysis close to biomass plantation sites, in contrast with FT fuels, for which costs are lower with centralised production. Comparison of the three biofuels using FT fuel as a reference (by further conversion of pellets and pyrolysis oil to FT fuels via entrained flow gasification) shows that it is more attractive to densify into and distribute pellets and pyrolysis oil early in the supply chain. FT fuels derived from pellets and pyrolysis oil result in lower fuel costs of 4.5 and 4.8 Euro/GJ respectively. Where biomass feedstock is not limited, large-scale conversion $\left(G W_{\text {th,in }}\right)$ directly to FT fuels using entrained flow gasification may result in much lower fuel cost.
\end{abstract}

\section{Introduction}

Bioenergy could be a major primary energy supply option in the future. Projections made by the Intergovernmental Panel on Climate Change (IPCC) envisage increased use of biofuels accompanied by technological innovation, increased agricultural productivity and cultivation on excess land [Nakicenovic and Swartz, 2000]. Current non-commercial use of biomass in Africa is largely inefficient and unsustainable, but potential exists for establishing largescale energy plantations and biomass conversion to highquality energy carriers such as ethanol and Fischer-Tropsch (FT) fuels. Smeets et al. [2004] estimated potential surplus land of up to 700 million hectares (Mha) in Sub-Saharan Africa that could be used to grow energy crops with annual yields of up to $317 \mathrm{EJ}$, assuming improvements in agricultural productivity of up to 8 times. Using scenario analysis, Hoogwijk [2004] also projected biomass production potential of up to $134 \mathrm{EJ} / \mathrm{yr}$ for Africa, using abandoned agricultural land and non-productive land.

International markets for biofuels are growing fast and this presents a major opportunity for developing countries to modernize agriculture and promote rural agro-forestry, generating jobs and revenues, as well as rehabilitate and utilize marginal land [Faaij, 2004; Broek, 2000]. Demand for modern bioenergy is particularly growing in OECD countries and international trade could trigger development of the biomass production potentials of key regions such as Sub-Saharan Africa. International bioenergy trade also appears to be possible at acceptable costs and energy use compared to regional utilization. (See Table 1 for cost ranges of biofuels.)

Mozambique is considered a promising region for biomass production within Southern Africa due to the relative abundance of land resources, favourable environmental conditions and low population density. Biomass 


\section{Articles}

Table 1. Short-term and long-term cost ranges of biofuels

\begin{tabular}{|l|c|c|c|c|c|c|}
\hline & $\begin{array}{c}\text { Rape methyl ester } \\
\text { (RME) }\end{array}$ & $\begin{array}{c}\text { Ethanol from sugar } \\
\text { or starch crops }\end{array}$ & $\begin{array}{c}\text { Ethanol from } \\
\text { woody biomass }\end{array}$ & $\begin{array}{c}\text { Hydrogen } \\
\text { from woody } \\
\text { biomass }\end{array}$ & $\begin{array}{c}\text { Methanol } \\
\text { from woody } \\
\text { biomass }\end{array}$ & $\begin{array}{c}\text { Bio-oil from } \\
\text { woody biomass }\end{array}$ \\
\hline $\begin{array}{l}\text { Cost range, short-term } \\
\text { (\$/GJ) }\end{array}$ & $\begin{array}{c}15-25 \\
\text { (north-west Europe) }\end{array}$ & $\begin{array}{c}15-25 \text { for sugar beet; } \\
8-10 \text { for sugar cane }\end{array}$ & $10-15$ & $8-10$ & $11-13$ & $10-15$ \\
\hline $\begin{array}{l}\text { Cost range, long-term } \\
\text { (\$/GJ) }\end{array}$ & n.a. & n.a. & $6-7$ & $6-8$ & $7-10$ & $6-10$ \\
\hline
\end{tabular}

Source: van Sark, 2003.

Notes

Longer-term projections for diesel and petrol: 8-11 \$/GJ; n.a. = not available

resource assessments [e.g., Hoogwijk, 2004; Smeets et al., 2004; Marrison and Larson, 1996] indicate considerable potential within the sub-region. Mozambique was also selected as a case-study for the region for the production and export of biofuels due to its relative vicinity to the ocean.

\subsection{Objectives}

This more detailed country-level study investigates the potential, economics and logistic options for Mozambique to produce biomass and biofuels for the export market. It covers three key elements:

1. potential biomass energy production assessment, taking into account regional diversity, current and projected demand for land and land use, and improvement potential of agricultural systems up to the year 2015;

2. biomass production performance of plantation woody crops at selected sites in six regions covering all major agro-ecological regions of Mozambique; and

3. techno-economic analysis and comparison of logistic chains for biomass export to the international market, using Rotterdam harbour as a final destination.

This paper is structured as follows. Section 2 presents a general background on Mozambique and is followed by an assessment of the land resources (Section 3). Section 4 provides biomass production potential estimates based on a methodology developed by Smeets et al. [2004]. This is followed by a description of the case-study areas in Section 5. An analysis of energy crop performance is then undertaken in Section 6 for selected case-study regions, after which supply chain logistics are analysed (Section 7). Section 8 summarises the main findings of the study.

\section{Mozambique}

Mozambique covers about 80 Mha of land with a 2500 $\mathrm{km}$ coastline along the Indian Ocean. Its population is estimated to be about 19 million, projected to increase to 28 million by 2025 . Population density is on average $22 / \mathrm{km}^{2}$ [INE, 2004]. Three macro-socio-ecological zones can be defined in Mozambique. The Northern region consisting of Niassa, Cabo Delgado and Nampula provinces covers about $50 \%$ of the total land area and supports about $33 \%$ of the population. The Central region, comprising Zambézia, Tete, Manica and Sofala provinces covers $29 \%$ of the land area with $41 \%$ of the population. The Southern region, which includes Inhambane, Gaza and Maputo provinces covers about $21 \%$ of the land area

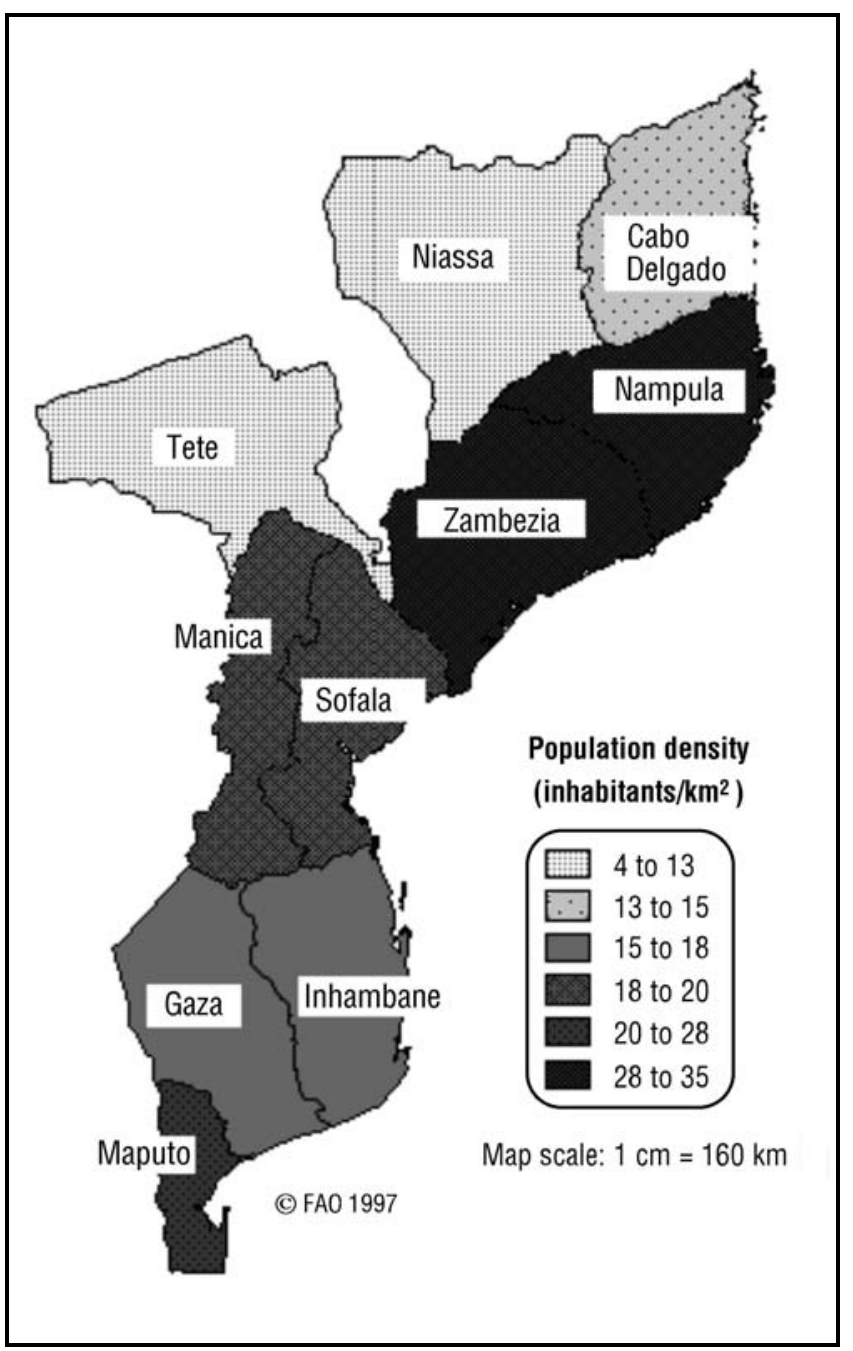

Figure 1. Regional population density distribution in Mozambique by province

Source: FAO/GIEWS, 2005

and has $26 \%$ of the national population [Wils, 2002]. (See Figure 1.)

Despite achieving very high economic growth ${ }^{[1]}$ during the 1990s, Mozambique has been reported as one of the poorest countries in the world, with an average per capita annual income of US\$ (1995) 185 in 2000. Nearly $70 \%$ of the population lives below the poverty line, with $40 \%$ on less than $\$ 1$ a day [UNDP, 2000]. Roughly $80 \%$ of the labour force is employed in the agricultural sector, which accounts for about $20 \%$ of GDP. Agriculture is 


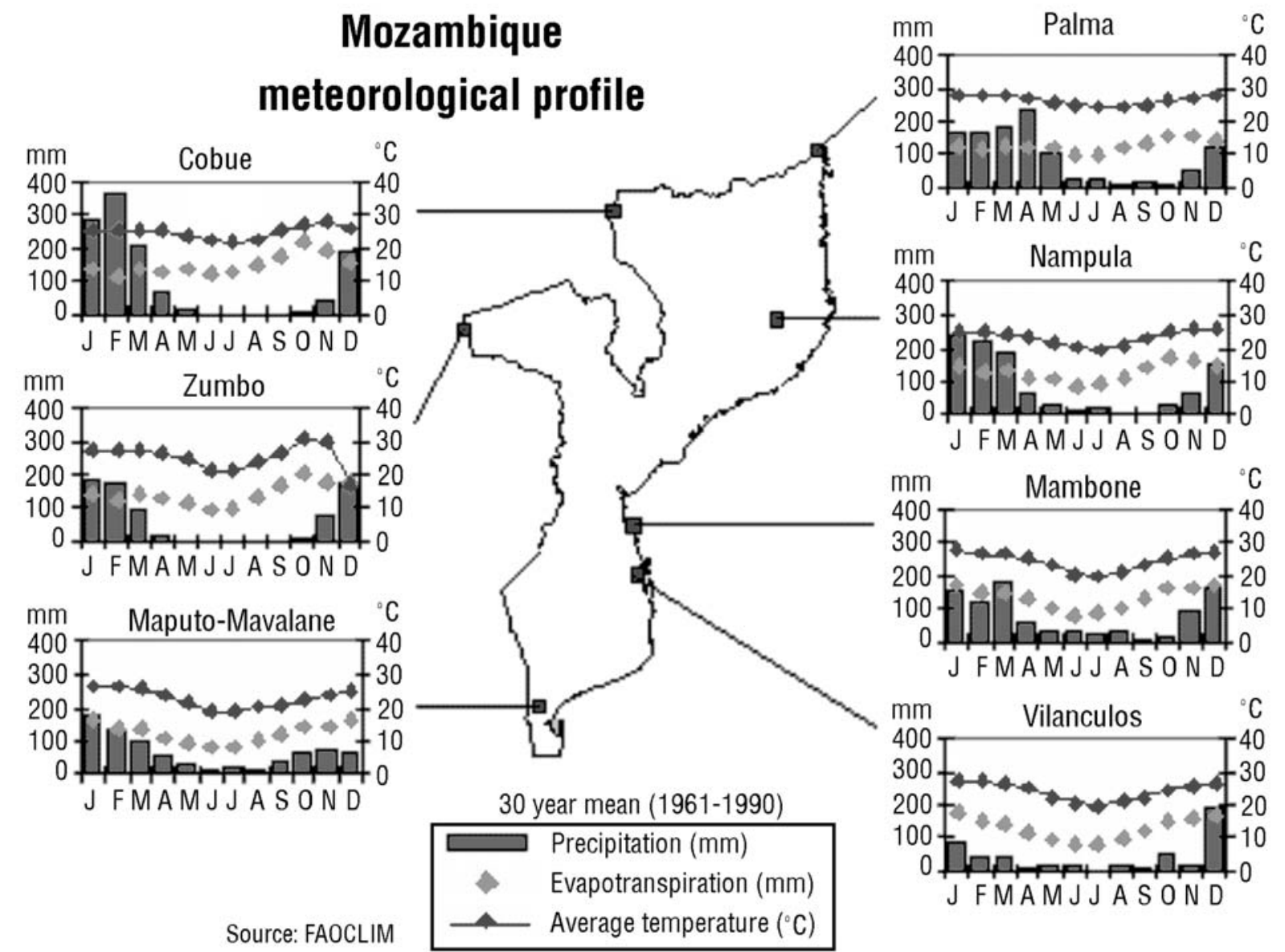

Figure 2. Distribution of broad climatic zones with agricultural suitability classes

Source: Wils, 2002

also the main activity for $95 \%$ of the households in rural areas [Bias and Donovan, 2003].

$64 \%$ of Mozambicans suffer from poor nutrition where calorie intake remains below the 2,100 kcal/aeu (aeu: adult equivalent unit) daily minimum. Rural Mozambicans obtain $70 \%$ of their food from own production. Food crop production is principally subsistence-based and much of agricultural production never reaches the market. The agriculturally productive North generally produces surplus food while deficits regularly occur in the South [UNDP, 2000; Bias and Donovan, 2003].

The socio-political economy of Mozambique has been heavily influenced by the post-independence legacy of internal conflict, regional destabilization and centrallyplanned economy. More than 6 million people were displaced by 27 years of war to the relative safety of urban areas, the coastline and major transport corridors. Infrastructure and services including roads, bridges and industrial plants were destroyed or abandoned. The post war-era has however seen a return of the population to rural areas, opening and expansion of farms and the reactivation of agricultural production under new market economy policies [Wils, 2002].

Mozambique exhibits great biophysiographic, geological and climatic diversity, from low-lying coastal and semi-arid plains $(<200 \mathrm{~m})$ to humid tropical mountainous regions $(>1,000 \mathrm{~m})$ as well as pockets of areas with temperate conditions with great variation of soil types, altitude, temperature and rainfall patterns [Moyo et al., 1993; Coelho and Littlejohn, 2000].

Bias and Donovan [2003] identified five broad climatic zones within Mozambique's predominantly tropical climate. These consist of the arid and dry semi-arid (mostly concentrated in the southern part of the country); wet semi-arid and sub-humid (dominating the Centre and North) and humid zones (in the interior highlands). (See Figure 2.)

There are two seasons, a dry winter season from April to September and a rainy summer season from October to March. Rainfall varies from $400 \mathrm{~mm}$ in the southwest to 2,600 $\mathrm{mm}$ per year in the mountainous North-west regions [Coelho and Littlejohn, 2000; Moyo et al., 1993]. 2.1. Land-use patterns

Table 2 below shows FAO data on land use. Woody vegetation extends over about $70 \%$ of the land territory of which about 19 Mha is considered productive forest with valuable timber [Da Silva et al., 1995; AfDB, 1995]. About 19 Mha is under shifting cultivation, of which $53 \%$ is under short fallow and $47 \%$ under long fallow. $1 \%$ of the land is under permanent crops. Currently, less than 


\section{Articles}

Table 2. Land-use classification (in thousands of $\mathbf{k m}^{2}$ )

\begin{tabular}{|c|c|c|c|c|c|c|c|c|c|c|c|}
\hline National classes of land use & $\begin{array}{c}\text { Cabo } \\
\text { Delgado }\end{array}$ & Gaza & $\begin{array}{c}\text { Inham- } \\
\text { bane }\end{array}$ & Manica & Maputo & $\begin{array}{l}\text { Nam- } \\
\text { pula }\end{array}$ & Niassa & Sofala & Tete & $\begin{array}{l}\text { Zambe- } \\
\text { sia }\end{array}$ & $\begin{array}{l}\text { Total } \\
\text { area }\end{array}$ \\
\hline Closed montane forests & 0 & 0 & 0 & 0.22 & 0 & 0 & 0.072 & 0.15 & 0 & 0.14 & 0.57 \\
\hline Medium closed montane forests & 0 & 0 & 0 & 0.21 & 0 & 0.076 & 0.06 & 0 & 0 & 0.20 & 0.55 \\
\hline Open montane forests & 0 & 0 & 0 & 0.26 & 0 & 0.048 & 0.016 & 0.052 & 0 & 0.42 & 0.79 \\
\hline Closed lowland forests & 1.76 & 1.47 & 2.22 & 1.45 & 0.78 & 1.56 & 1.62 & 3.23 & 1.26 & 3.17 & 18.53 \\
\hline Medium closed lowland forests & 3.26 & 2.97 & 7.65 & 3.98 & 2.64 & 4.18 & 5.68 & 4.90 & 4.24 & 9.62 & 49.13 \\
\hline Open lowland forests & 16.36 & 8.87 & 17.33 & 9.49 & 2.52 & 10.14 & 18.59 & 9.58 & 11.33 & 19.72 & 123.93 \\
\hline Thickets & 20.17 & 10.86 & 9.16 & 12.04 & 2.84 & 10.49 & 38.64 & 10.19 & 20.85 & 13.86 & 149.09 \\
\hline Shrub & 4.69 & 11.25 & 2.83 & 8.09 & 2.73 & 2.06 & 15.98 & 8.65 & 19.26 & 4.00 & 79.54 \\
\hline Wooded grassland & 8.28 & 15.76 & 8.28 & 11.52 & 3.18 & 2.88 & 14.61 & 10.84 & 18.18 & 6.61 & 100.14 \\
\hline Closed mangroves & 0.16 & 0.004 & 0.11 & 0 & 0.028 & 0.18 & 0 & 0.76 & 0 & 0.91 & 2.14 \\
\hline Sparse mangroves & 0.12 & 0 & 0.084 & 0 & 0.10 & 0.37 & 0 & 0.50 & 0 & 0.68 & 1.85 \\
\hline Grassland & 1.68 & 6.72 & 1.75 & 2.40 & 2.78 & 0.80 & 2.34 & 7.07 & 4.94 & 5.06 & 35.56 \\
\hline Man-made forests ${ }^{[4]}$ & 0 & 0 & 0 & 0.33 & 0.024 & 0 & 0.008 & 0.008 & 0 & 0.008 & 0.38 \\
\hline Agriculture - permanent cultivation & 0.15 & 2.76 & 0.67 & 0.068 & 1.67 & 0.86 & 0.040 & 0.84 & 0.016 & 3.07 & 10.14 \\
\hline $\begin{array}{l}\text { Agriculture - shifting cultivation, } \\
\text { short fallow }\end{array}$ & 12.78 & 8.43 & 8.21 & 4.17 & 4.64 & 30.76 & 7.45 & 3.19 & 7.76 & 13.24 & 100.62 \\
\hline $\begin{array}{l}\text { Agriculture - shifting cultivation, } \\
\text { long fallow }\end{array}$ & 5.98 & 5.67 & 7.13 & 7.29 & 2.34 & 12.77 & 14.68 & 7.15 & 8.96 & 18.63 & 90.60 \\
\hline Dunes & 0 & 0.10 & 0.14 & 0 & 0.10 & 0.32 & 0 & 0.028 & 0 & 0.17 & 0.86 \\
\hline Barren lands & 0.46 & 0.43 & 0.37 & 0.004 & 0.040 & 1.46 & 0.28 & 0.48 & 0.47 & 0.70 & 4.70 \\
\hline Urban and other areas & 0.23 & 0.12 & 0.076 & 0.064 & 0.17 & 0.21 & 0.16 & 0.076 & 0.28 & 0.060 & 1.45 \\
\hline Inland water bodies & 0.30 & 1.19 & 1.02 & 0.14 & 0.31 & 0.21 & 7.10 & 0.14 & 1.77 & 0.21 & 12.39 \\
\hline Rios & 0.43 & 0.43 & 0.22 & 0.47 & 0.048 & 0.11 & 0.44 & 0.90 & 0.78 & 0.82 & 4.65 \\
\hline Total & 76.82 & 77.04 & 67.26 & 62.20 & 26.96 & 79.48 & 127.76 & 68.71 & 100.09 & 101.28 & 787.61 \\
\hline
\end{tabular}

Source: Mangue, 2000

$18 \%$ of the 36 Mha of suitable agricultural land is actually being cultivated. Overall, agricultural land ${ }^{[2]}$ is estimated to be about 48 Mha of which permanent pasture is about 44 Mha [Mangue, 2000] ${ }^{[3]}$. There is little investment in timber plantations, which represent less than $0.1 \%$ of the total land area.

Cultivated land is projected to increase by $26 \%$ to about 8 Mha in 2015. There are very few incidences of land-use conflict, they are generally isolated, and those reported have been confined to the very densely populated districts in Zambézia, Maputo and Gaza [UNDP, 2000]. (See Figure 1.)

Land and all natural resources in Mozambique belong to the state, which grants user rights to the communities in the rural areas, to urban-dwellers or to both local and foreign private entities. Rural subsistence farming constitutes the main land use, where rural communities own small plots, with exclusive use rights but without title deeds. This land is obtained through occupation on the basis of traditional local structures and rules. Access to forest resources and pasture is however common. In contrast, the private sector requires to obtain a lease for development of large-scale agricultural activities. In addition, the private sector requires concessions to exploit natural resources including harvesting forest products and land for private grazing [Nhantumbo, 2000; Reyes, 2003].

\section{Assessment of biomass resources}

The focus in this study is on dedicated bioenergy crops, because this is the source of bioenergy crops with the highest potential in Mozambique compared to other sources such as forestry logging residues or agricultural residues. The potential of bioenergy crops is determined by the availability of land and the yield level. In this paper, a bottom-up approach is applied to estimate the land availability and the productivity using the "Global Quickscan" methodology developed by Smeets [Smeets et al., 2005]. Two basic sustainability criteria provide the starting-points for this approach. First, competition between food and bioenergy production should be avoided 


\section{Articles}

Table 3. Key variables for Mozambique, their assumed values for 1998 and 2015 and the main data sources used

\begin{tabular}{|c|c|c|c|c|c|}
\hline Parameter & Source & 1998 & 2015 & Unit & Remark \\
\hline Population & UNDP, 2003 & 17.6 & 31.3 & million & Medium growth scenario \\
\hline Per capita food consumption & FAO, 2003b & 1924 & $2869^{[1]}$ & $\mathrm{kcal} / \mathrm{cap} /$ day & $\begin{array}{l}\text { Figures for } 2015 \text { are increased to compensate for } \\
\text { undernourishment. }\end{array}$ \\
\hline Economic growth & FAO, 2003b & $2.6^{[2]}$ & n.a. ${ }^{[3]}$ & $\% / y r$ & $\begin{array}{l}\text { World Bank economic projections are used as } \\
\text { exogenous assumptions in the FAO projections } \\
\text { on food consumption. }\end{array}$ \\
\hline Climate change & n.a. & Excluded & Excluded & - & $\begin{array}{l}\text { The impact of climate change on agriculture is } \\
\text { limited compared to the technological potential } \\
\text { and thus excluded. }\end{array}$ \\
\hline $\begin{array}{l}\text { Level of advancement of agri- } \\
\text { cultural production }\end{array}$ & & Low & Various & - & See text \\
\hline Animal production system & $\begin{array}{l}\text { IMAGEteam, } \\
2001\end{array}$ & $\begin{array}{l}\text { Mainly } \\
\text { pastoral }\end{array}$ & $\begin{array}{l}\text { Mixed or } \\
\text { landless }\end{array}$ & - & See text \\
\hline Feed conversion efficiency & $\begin{array}{l}\text { IMAGEteam, } \\
2001\end{array}$ & $70-37^{[4]}$ & $4.1-3.6^{[4]}$ & $\begin{array}{l}\mathrm{kg} \mathrm{dm} \text { feed/ } \\
\mathrm{kg} \text { product }\end{array}$ & $\begin{array}{l}\text { Data are based on an intermediate level of } \\
\text { advancement of agricultural technology and a } \\
\text { mixed animal production system }\end{array}$ \\
\hline
\end{tabular}

\section{Notes}

1. The per capita consumption is increased by some one-third to avoid undernourishment.

2. Average for the period $1998-2015$

3. n.a. = not available

4. The first figure is for bovine meat and the second for poultry meat.

and, therefore, food production is given priority above bioenergy production. Second, deforestation to make land available for food or bioenergy production is considered unsustainable and should be avoided. Therefore, the use of land for bioenergy production from dedicated bioenergy crops is limited to surplus land not required for food production and land not suitable for food or feed crop production. The total agricultural area is kept constant at the base-year level. Consequently, surplus land is only achieved when the (assumed) increase in food production efficiency outpaces the increase in food demand. The presumed increases in efficiency of food production can be realised by the application of more efficient agricultural production systems and the geographical optimisation of crop production, i.e., optimising land allocation.

Therefore, key factors when estimating the potential of bioenergy crops are (adjusted from Smeets et al. [2005]) the demand for food and feed, the agricultural production efficiency and the suitability of the present agricultural land for crop production, as described below. Table 3 gives an overview of the values and data sources for the key variables included.

Demand for food. The demand for food is modelled as a function of population growth and per capita food intake. The demand for food is analysed separately for vegetable products, animal products and marine food, because of differences in production systems, land-use requirements and the methodologies used to translate these demands into land-use patterns.

Demand for feed and land use. The demand for feed and the land use required for the production of animal products is dependent on the production system, the quality of the feed, the animal species and the level of technol- ogy ${ }^{[5]}$. In a pastoral animal production system, most feed comes from fodder and permanent pastures, leading to low feed conversion efficiencies ${ }^{[6]}$ and the use of large pasture areas. The other extreme is a virtually landless industrialised production system, in which all animals are kept inside under controlled conditions and all feed comes from feed crops and residues, resulting in high feed conversion efficiencies and a limited use of land for feed crop production. On the basis of these factors the demand for feed from permanent pastures is estimated. The supply of feed from permanent pastures is kept constant, because an increase could lead to an expansion of the area under permanent pasture, resulting in deforestation or higher grazing intensities, which in turn could lead to soil erosion and other problems related to overgrazing.

Demand for crops and land use. The cropland required for the production of feed and food crops is dependent on the efficiency of crop production, i.e., the crop yields. Crop yields are determined by the following key factors: the productivity of the cropland available for crop production determined by natural conditions (rainfall, radiation, temperature, soil permeability, fertility etc.), the level of advancement of agricultural technology applied and the geographical optimisation of land-use patterns. Five potential agricultural technological development scenarios are envisaged, as defined in Table 4.

Simple allocation rules are used to determine the area of suitable cropland claimed by various land-use categories (e.g., forests, permanent pastures, built-up areas). The demand for crops is translated into land use by allocating crop production to the area with the most favourable agroecological conditions of the total area available for crop production, thereby minimizing the agricultural land use 


\section{Articles}

Table 4. Level of advancement of agricultural technology

\begin{tabular}{|c|l|l|}
\hline $\begin{array}{l}\text { Level of agricul- } \\
\text { tural technology }\end{array}$ & Water supply & Description \\
\hline Low & Rain-fed & $\begin{array}{l}\text { No use of fertilizers, pesticides or improved seeds or breeds, specialised health care for animals } \\
\text { and calf-rearing activities, equivalent to subsistence farming as in rural parts of Africa and Asia }\end{array}$ \\
\hline Intermediate & Rain-fed & $\begin{array}{l}\text { Some use of fertilizers, pesticides, improved seeds or breeds, animal health care and mechanical } \\
\text { tools }\end{array}$ \\
\hline High & Rain-fed & $\begin{array}{l}\text { Full use of all required inputs and management practices as in advanced commercial farming at } \\
\text { present found in the USA and the EU }\end{array}$ \\
\hline Very high ${ }^{[1,2]}$ & Rain-fed & $\begin{array}{l}\text { Use of a high level of technology on very suitable and suitable soils, medium level on moderately } \\
\text { suitable areas and low level on moderately and marginally suitable areas. The rationale is that it is } \\
\text { unlikely to make economic sense to cultivate moderately and marginally suitable areas at the high } \\
\text { technology level, or to cultivate marginally suitable areas at the medium technology level. }\end{array}$ \\
\hline Very high & Rain-fed/ \\
irrigated & $\begin{array}{l}\text { Same as a very high input system, but including the impact of irrigation on yields and areas } \\
\text { suitable for crop production. }\end{array}$ \\
\hline
\end{tabular}

Notes

1. The very high level of agricultural technology is applicable for crop production only; the low to high level of agricultural technology applies to both the production of crops and the production of animal products.

2. This level of technology is called "mixed input system" in the original IIASA classification, but is dubbed "very high" production system to avoid confusion with the term mixed (animal) production system and because it is generally more efficient than a high-level-of-technology production system.

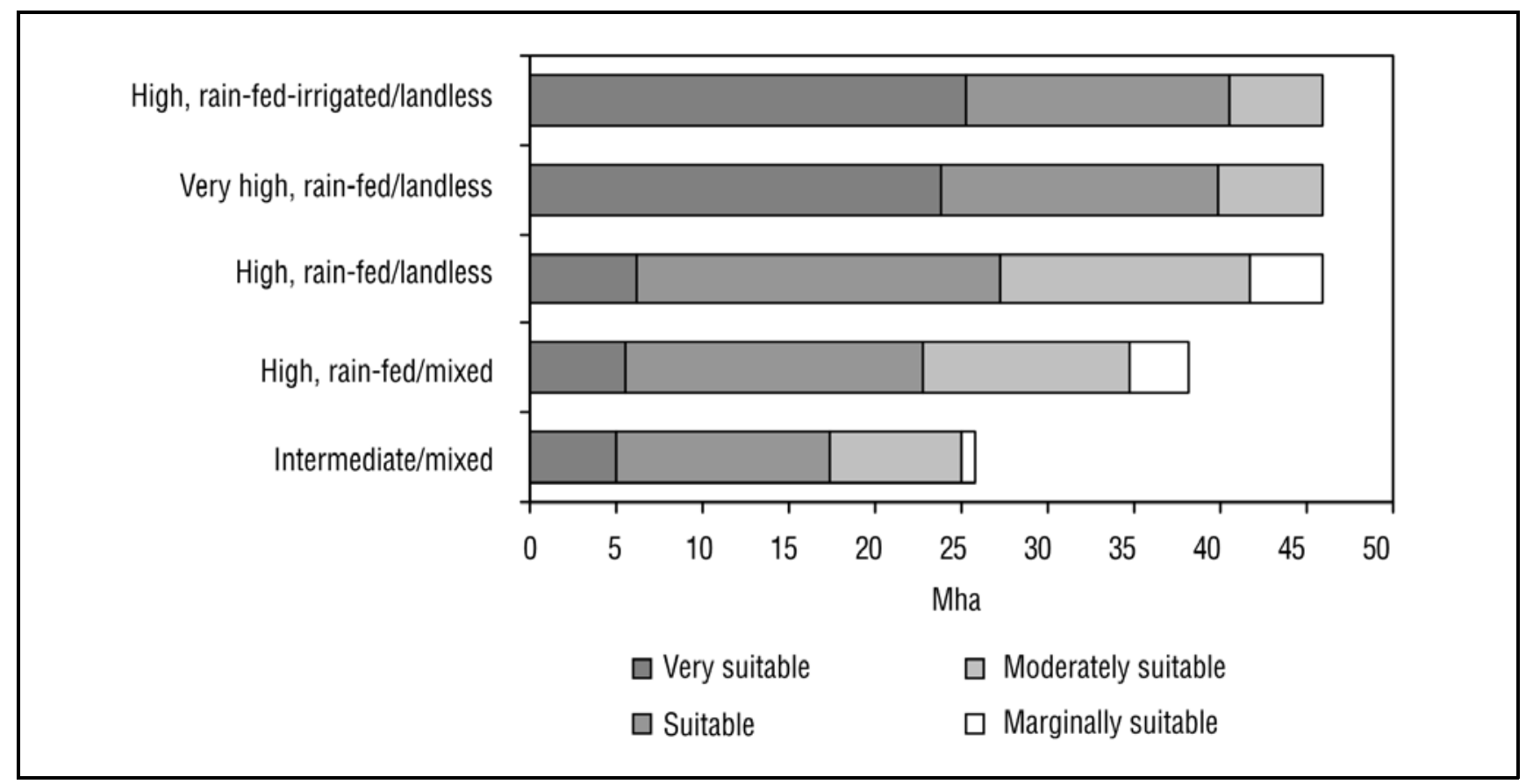

Figure 3. Potential surplus agricultural land in 2015 in Mozambique, depending on the level of advancement of agricultural technology and the animal production system and taking into account growing demand for food

Note

FAO defines "land suitability" as "the fitness of a given type of land for a specified kind of land use" [Rossiter, 1994]. In our case, the object is suitability for agricultural production based on combinations of constraints. We use five levels of suitability which indicate the degree of suitability (i.e., very suitable (VS), suitable (S), moderately suitable (MS), marginally suitable (mS) and not suitable (NS)).

and leaving the least productive areas for bioenergy crop production. For further information on the methodology and data, see Smeets et al. [2005].

The efficiency of food production is thus a key parameter for the potential land availability and suitability for bioenergy crop production. Currently, the productivity of agriculture in Mozambique is very low compared to what is technically feasible. Agricultural systems are dominated by small-scale rain-fed subsistence production based on manual cultivation techniques using hand tools and little use of purchased inputs ${ }^{[7]}$. Average cereal yields are below 1 tonne per ha $(\mathrm{t} / \mathrm{ha})$, while agro-ecologically attainable yields in a high-input agricultural production system of the three most important cereals range from $8 \mathrm{t} /$ ha to 12 t/ha [FAO, 2002; 2003a]. The feed conversion efficiency in Mozambique is estimated at around $70 \mathrm{~kg}$ dry matter 


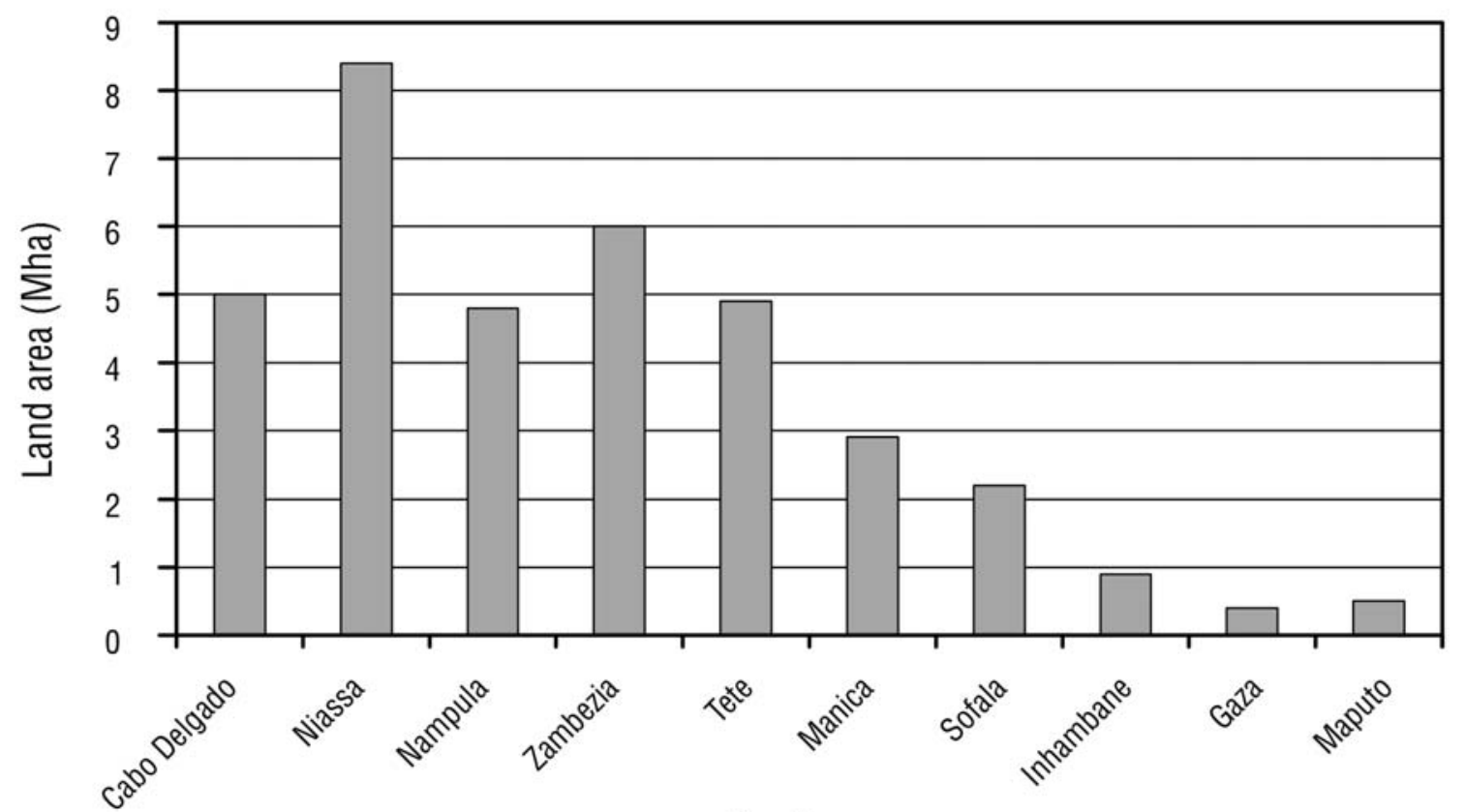

Province

Figure 4. Distribution of land suitable for rain-fed agriculture

Source: AfDB, 1995

(dm) feed per $\mathrm{kg}$ bovine meat in a pastoral production system, while in the industrialised production system used in the EU the average feed conversion efficiency it is 15 $\mathrm{kg} \mathrm{dm} / \mathrm{kg}$ meat. These data indicate that there are large (technological) potentials to increase the efficiency of food production.

The potential to increase the efficiency of food production and generate surplus agricultural land for bioenergy crop production is analysed by varying the level of agricultural technology.

Figure 3 shows the surplus agricultural land in 2015, based on the five levels of agricultural technology described; projections for other parameters are based on the data shown in Table 3. Results for a situation where the demand for food cannot be met are excluded because stable and sufficient food supplies are deemed to be a precondition for sustainable bioenergy provision.

The results show that in 2015 up to 45 Mha of the 48 Mha currently used could (in theory) be made available for bioenergy crop production in Mozambique, depending on the level of advancement of agricultural technology and the animal production system. Very substantial increases in the food production efficiency could be realised: average crop yields could increase by a factor of 4.9 to 8.9 and the average feed conversion efficiency for bovine meat and poultry meat increase by a factor of 4.5 and 1.3, respectively. When a low level of technology and/or a landless or mixed animal production system is applied, then the efficiency of food production is insufficient to meet the demand and results are therefore excluded. In this study, we use the results of the intermediate level of agricultural technology in combination with a mixed animal production system, because this requires the lowest increase in efficiency considered here and seems more feasible in the short term.

The (theoretically) most productive regions are in the northern and central interior of the country, where the soil conditions are better and rainfall is more abundant than in the southern regions. (See Figures 4 and 5.)

Since model data is national, there is need to translate it into regional data to enable identification of suitable plantation sites for energy crops. To estimate surplus land availability in each region of Mozambique, we allocated the national surplus land according to the agro-ecological suitability ${ }^{[8]}$ of each region. This was achieved by estimating the total land in each suitability class falling under each region according to the relative abundance of that suitability class in that region. Figure 5 shows the estimated land availability potentials in each region by suitability class.

\section{Bioenergy production potential}

Using the identified land resources, biomass production potential from energy crops (E) is subsequently estimated for each region (r) as a function of the identified surplus land $\left(\mathrm{A}_{\mathrm{i}}\right)$ in each suitability class (i) and the expected yields $\left(\mathrm{P}_{\mathrm{i}}\right)$ for that suitability class as follows:

$$
\mathrm{E}=\sum_{\mathrm{i}, \mathrm{r}} \mathrm{A}_{\mathrm{i}} \times \mathrm{P}_{\mathrm{i}} \times \mathrm{HV}
$$

where $\mathrm{HV}$ is the heating value of dry biomass from eucalyptus $\left(19.4 \mathrm{GJ} / \mathrm{t}_{\mathrm{dm}}\right)$. (All energy values for fuels are higher heating values unless otherwise noted.)

Expected yields for each region are shown in Table 5. The total biomass production potential from eucalyptus plantations in Mozambique was estimated to be about 6.7 EJ per annum ${ }^{[9]}$ with $1.83 \mathrm{EJ}$ from the highly productive 


\section{Articles}

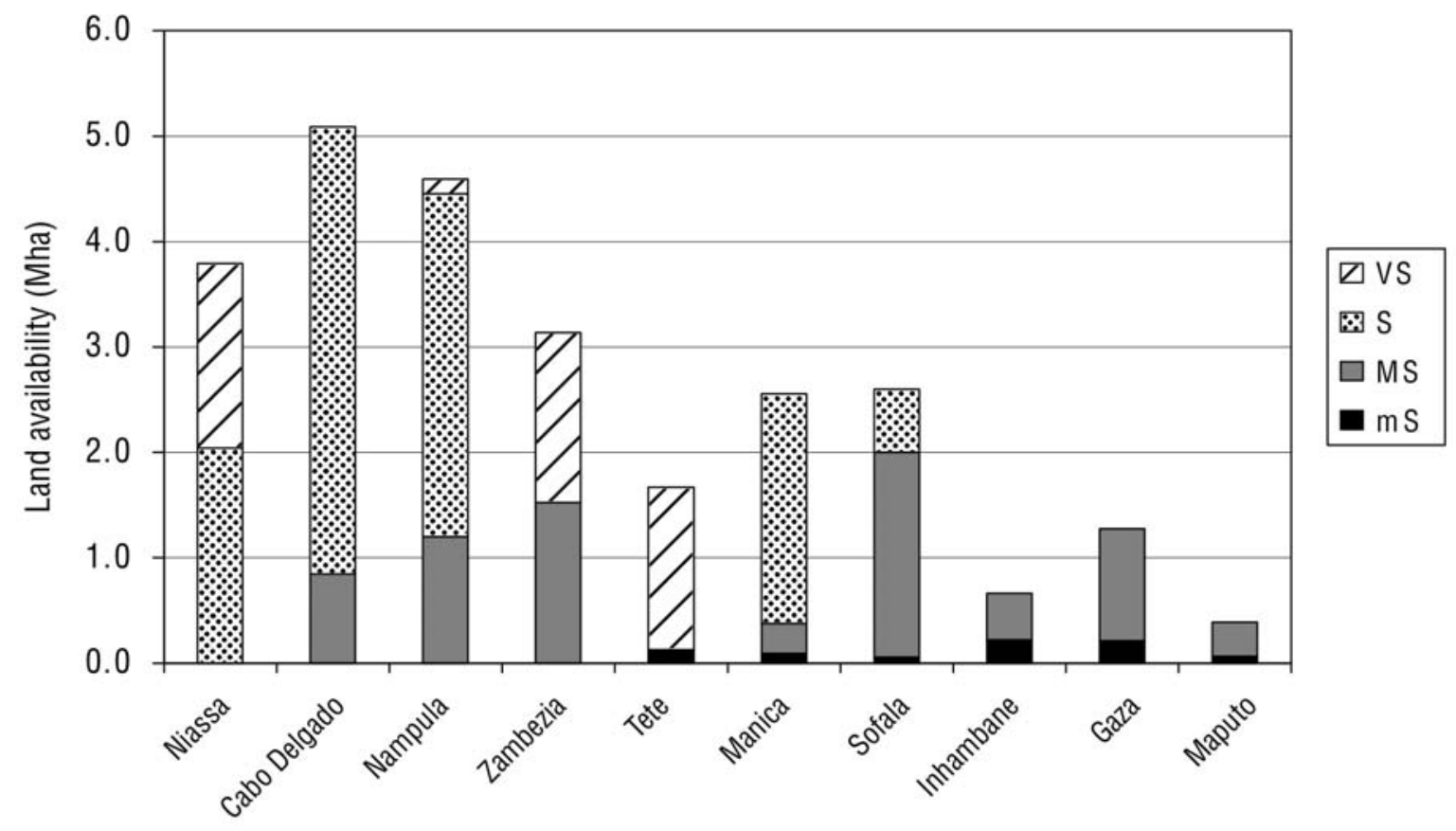

Region

Figure 5. Potential land availability for energy crop production by region (under the intermediate technology management system - 2015 projection). See Notes to Figure 4 for explanation of abbreviations in key.

Table 5. Estimated annual biomass production potentials by region (PJ)

\begin{tabular}{|c|c|c|c|c|c|c|}
\hline \multirow[t]{2}{*}{ Province } & \multicolumn{5}{|c|}{ Land productivity class } & \multirow[t]{2}{*}{ Total } \\
\hline & Highly productive & Productive & Semi-arid & Coastal & Dry arid & \\
\hline Niassa & 636 & 540 & - & - & - & 1,176 \\
\hline Cabo Delgado & - & 1,121 & - & 165 & - & 1,286 \\
\hline Nampula & 50 & 859 & - & 234 & - & 1,144 \\
\hline Zambézia & 586 & - & - & 298 & - & 883 \\
\hline Tete & 561 & - & - & - & 15 & 576 \\
\hline Manica & - & 576 & 55 & - & 11 & 642 \\
\hline Sofala & - & 159 & 231 & 148 & 7 & 545 \\
\hline Inhambane & - & - & - & 86 & 27 & 113 \\
\hline Gaza & - & - & - & 207 & 26 & 234 \\
\hline Maputo & - & - & - & 63 & 8 & 71 \\
\hline Total & 1,833 & 3,254 & 285 & 1,203 & 95 & 6,670 \\
\hline
\end{tabular}

regions, 3.25 EJ from the productive regions, 1.2 EJ from coastal areas, 0.1 EJ from semi-arid zones and 0.29 EJ from arid zones. (See Table 5.) The productive region of Cabo Delgado has the highest biomass production potential of about 1.2 EJ while the least is $71 \mathrm{PJ}$ in arid Maputo. Figure 6 shows the geographic distribution of the biomass production potential for the various ecological regions of Mozambique.

\section{Case-studies}

The case-studies focussed on six provinces to reduce the number of possible scenarios but still covering all major agro-ecological regions as shown in Figure 7. Selection of sites was based on the relative availability of excess land (see Figure 5), population density (see Figure 1), intensity of agricultural crop production and availability of infrastructure (looking at rail and river access, see Figure 8). The provinces of Niassa and Cabo Delgado were selected under the productive category (very suitable to suitable areas), Sofala under the semi-arid regions (moderately suitable), Zambézia and Gaza under the coastal (moderately suitable) and Inhambane under the 


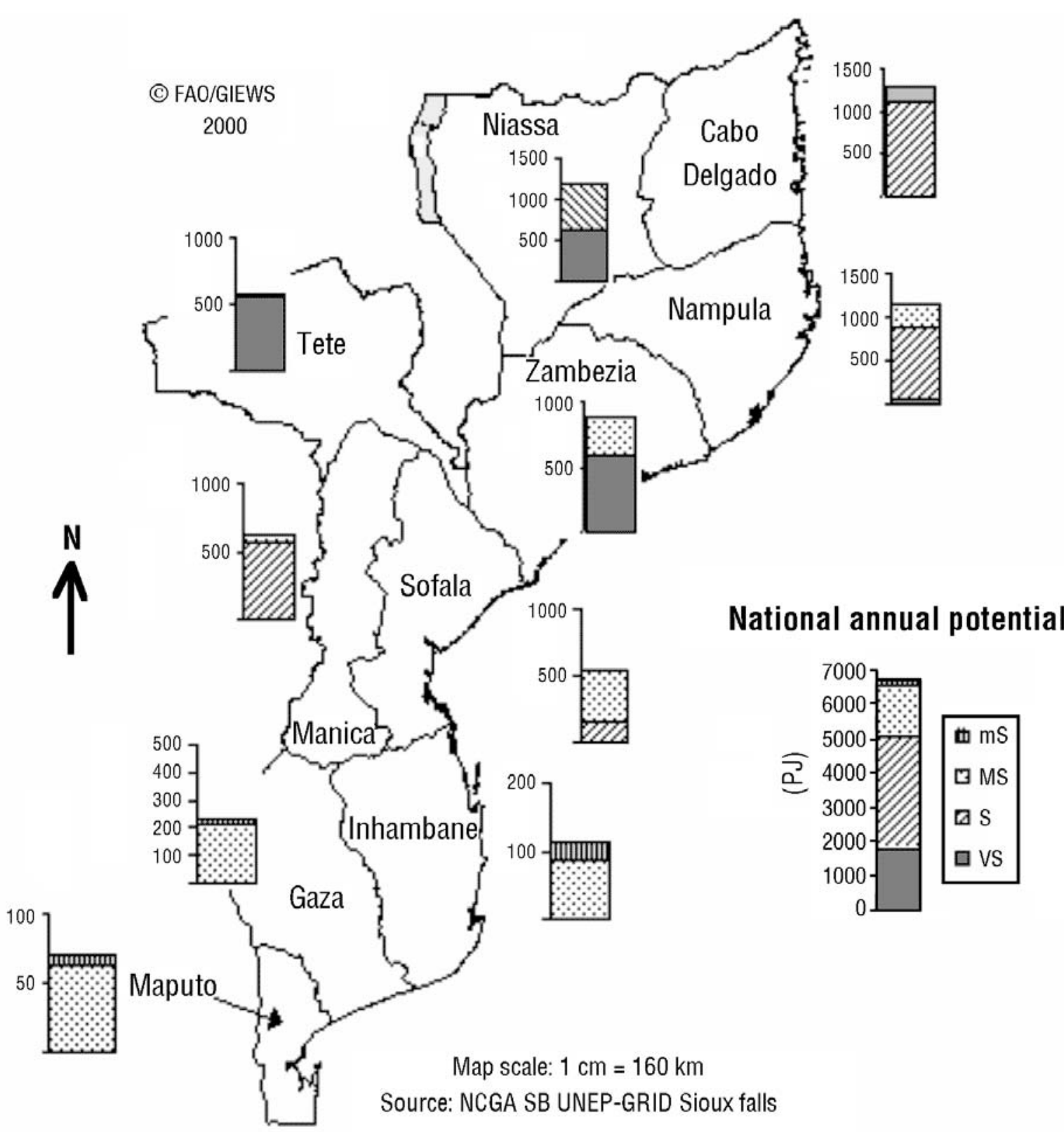

Figure 6. Regional biomass annual production potential in Mozambique (PJ) (2015)

arid (marginally suitable).

These regional case-studies enable comparisons of the production potential from the various ecological regions and give insights into the advantages, constraints and challenges posed by supplying biomass from each region. Biomass yields are highest in the productive zones but logistics are more complex since these are regions located in the interior. The arid and coastal zones give lower biomass yields, which make production more costly but supply logistics are much easier and there is less competition with food production ${ }^{[10]}$. Coastal regions would naturally achieve the lowest logistic costs, but most coastal regions are more densely populated.

\subsection{Residues}

Additional biomass potential also exists from other sources such as forestry residues, timber-processing activities and agricultural waste. The 19 Mha of land in Mozambique considered to be productive forests (comprising 120 different commercial species) has a potential sustainable extraction of about $0.025 \mathrm{~m}^{3} / \mathrm{ha} / \mathrm{yr}^{[11]}$ or $500,000 \mathrm{~m}^{3}$ cut per year [NDC, 2004] $]^{[12]}$. Potential biomass from forest logging residues is estimated to be about 850 TJ while $1.9 \mathrm{PJ}$ of biomass is potentially available from waste in timber processing industries, giving a combined residue potential of about 2.7 PJ. The latter is based on potential annual timber-processing capacity of about $500,000 \mathrm{~m}^{3}$ and a recoverability fraction of $55 \%$ [Smeets et al., 2004]. Logistics for recovery of logging residues are more costly compared to dedicated energy crops due to the dispersed nature of forest resources and 


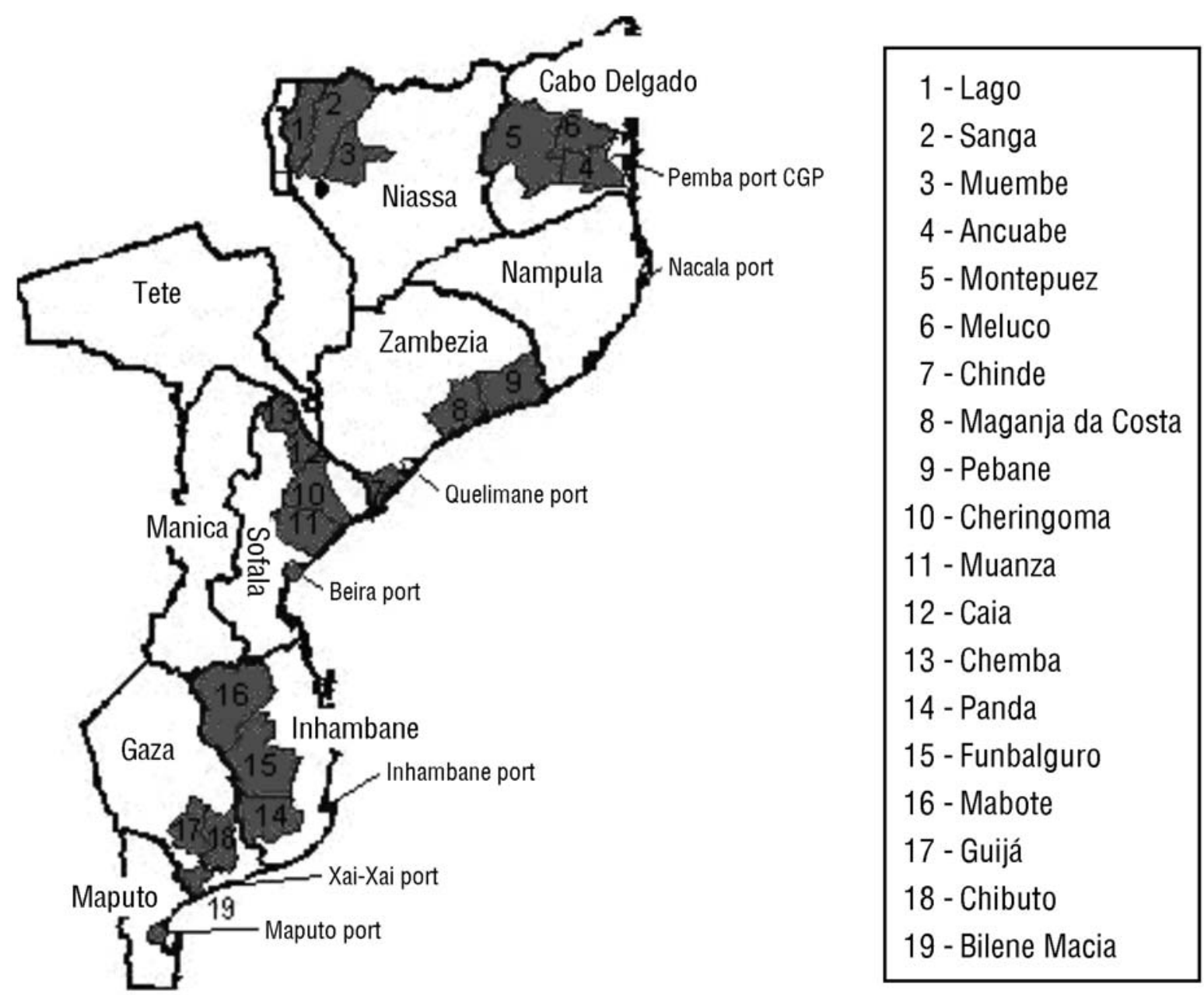

Figure 7. Map of Mozambique showing selected case-study regions

harvesting patterns in Mozambique [Fath, 2002; Reyes, 2003]. Timber-processing waste is a more attractive source of biomass since its costs are negligible and processing can be done at the production site. However, the total potential is much lower compared to energy crops and availability is tied to forestry industry production.

There is limited biomass potential from agricultural harvesting and processing residues because of the dispersed and subsistence nature of agricultural activities. Logistics for collecting and processing such scattered resources would be very costly. Furthermore, agricultural residues are also used for other purposes such as animal feed, fertiliser and energy, and net availability is therefore generally low [Maya et al., 1993].

However, bioenergy potential from the agricultural sector also exists in the sugar industry which is currently being revived. Current sugar cane production at six mills averages about 1.8 million tonnes (Mt) of cane per year. Production is expected to increase to about $3.3 \mathrm{Mt}$ of cane by 2010 [Locke, 2003]. It is possible to directly extract 39 million litres $(\mathrm{Ml})$ of ethanol ${ }^{[13]}$ at current production rates and up to $68 \mathrm{Ml}$ by 2010 . Bagasse residues from cane processing are another source of biofuel, which can be combusted to provide heat and for electricity. Using an average of $31 \%$ bagasse content for Southern Africa, current bagasse output is estimated to be about 560,000 t per annum with potential energy output of 4.2 PJ (LHV). In 2010 bagasse output is expected to increase to 994,000 t/yr (7.5 PJ, LHV) [Deepchand, 2001].

\section{Economics of energy crop production}

Development of energy crop plantations involves site preparation, planting, maintenance and harvesting. Specific activities in each phase depend on the site quality which influences the degree of site preparation necessary; choice of species, planting density, and rotations; required cultural management and soil amendments (fertilization, weed control, animal control, and pest management); as well as transport and logistics [Broek, 2000; Perlack et al., 1997].

Production costs are mainly influenced by the rotation regimes and productivity in each region. The derived costs given in this study are indicative and actual costs depend on specific site conditions, management system and silvicultural treatments.

Eucalyptus growth is susceptible to competition from weeds and soil nutrients. Therefore, patterns of weeding $^{[14]}$ and fertiliser application are important determinants 


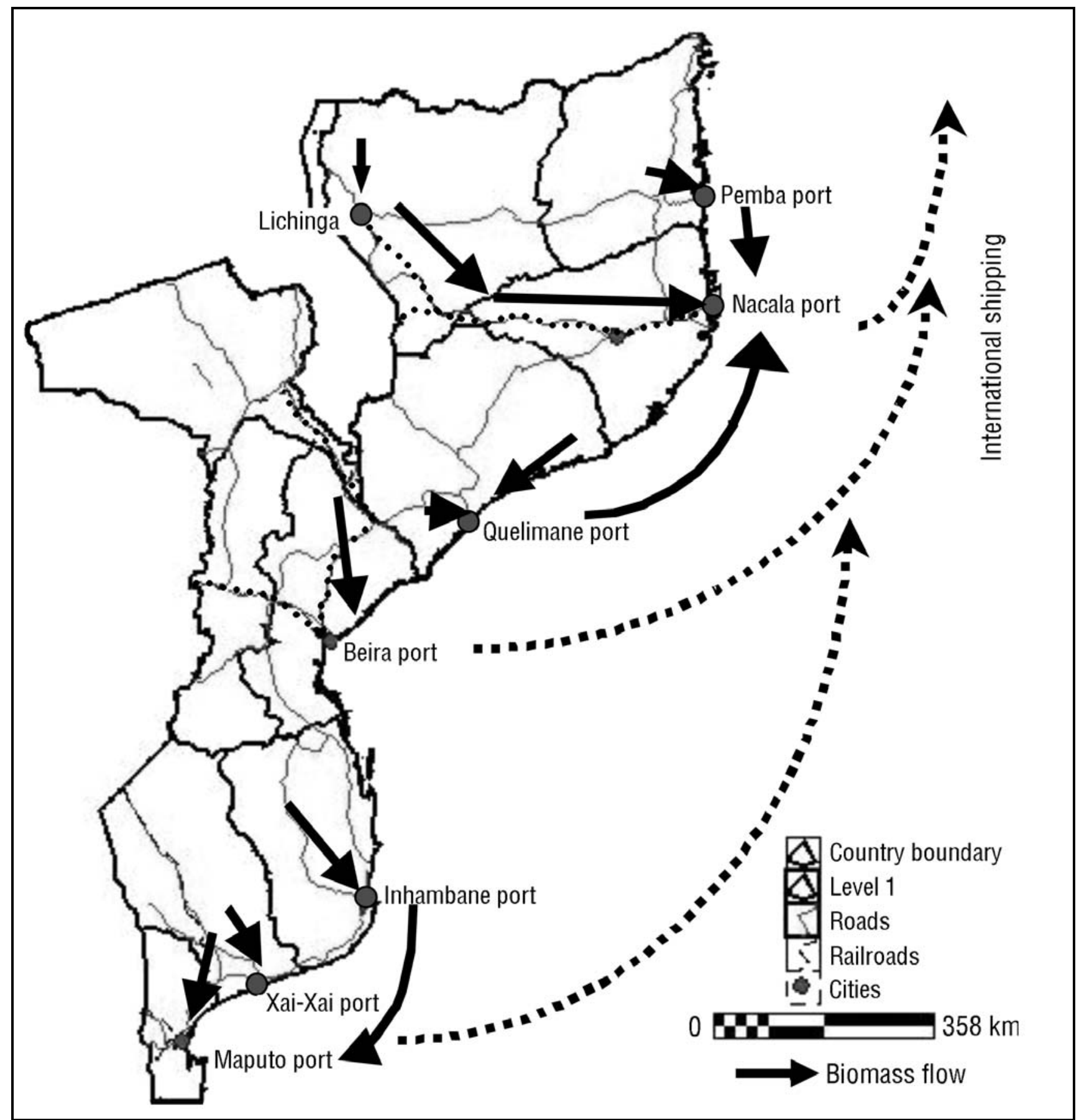

Figure 8. Infrastructure map of Mozambique showing biomass supply corridors

of yield levels [Perlack et al., 1997]. The planting density and rotation schemes also influence the growing characteristics and biomass yields. Generally, labour costs and land rent are low in Mozambique ${ }^{[15]}$.

There is limited documentation on plantation forestry management specific to Mozambique to assess costs of growing eucalyptus. Apart from government projects, there is only one major reported commercial plantation at the recently privatised IFLOMA Industries [Mangue, 2000]. No operational data on this plantation could be found within the time-frame of the study. We thus used limited literature from government-run forestry activities in Mozambique [Mangue, 2000; Macucule, 2001], discus- sions with the Mozambican Forestry Directorate and experiences from other Southern African countries [Lingen, 2004; Mabvurira and Pukkala, 2002; Kwesha and Matarira, 2004; Ugalde and Perez, 2001]. As a guide to eucalyptus plantation in a developing country setting, we adapted the cost structure given by Broek [2000] employed by commercial plantations in Nicaragua. (See Tables 6, 7 and 8.) Differences in costs for Mozambique are mainly related to labour, land rent and other inputs such as fertiliser and agrochemicals. The occurrence of the cost items varies depending on the selected rotation regime as well as on other site-specific factors.

Current rotation lengths of fuelwood plantations are 


\section{Articles}

Table 6. Example of frequency and timing of cost items in eucalyptus plantations (productive regions)

\begin{tabular}{|c|c|c|c|c|c|c|c|c|c|}
\hline \multirow{2}{*}{\multicolumn{2}{|c|}{ Year }} & \multicolumn{8}{|c|}{ Frequency of cost items per year } \\
\hline & & Land rent & $\begin{array}{c}\text { Site } \\
\text { preparation }\end{array}$ & Planting & Weeding & $\begin{array}{l}\text { Pesticide } \\
\text { application }\end{array}$ & $\begin{array}{l}\text { Fertiliser } \\
\text { application }\end{array}$ & Security & Harvest \\
\hline First rotation & 1 & 1 & 1 & 1 & 5 & 1 & 1 & 1 & - \\
\hline & 2 & 1 & - & - & 3 & 1 & 1 & 1 & - \\
\hline & 3 & 1 & - & - & 3 & 1 & 1 & - & - \\
\hline Second rotation & 4 & 1 & - & - & 3 & 1 & 1 & 1 & 1 \\
\hline & 5 & 1 & - & - & - & - & 1 & 1 & - \\
\hline & 6 & 1 & - & - & 1 & 1 & 1 & - & - \\
\hline Third rotation & 7 & 1 & - & - & 3 & 1 & 1 & 1 & 1 \\
\hline & 8 & 1 & - & - & - & - & 1 & 1 & - \\
\hline & 9 & 1 & - & - & 1 & 1 & 1 & - & - \\
\hline Fourth rotation & 10 & 1 & - & - & 3 & 1 & 1 & 1 & 1 \\
\hline & 11 & 1 & - & - & - & - & 1 & 1 & - \\
\hline & 12 & 1 & - & - & 1 & 1 & 1 & - & - \\
\hline Final harvest & 13 & 1 & - & - & - & - & - & - & 1 \\
\hline
\end{tabular}

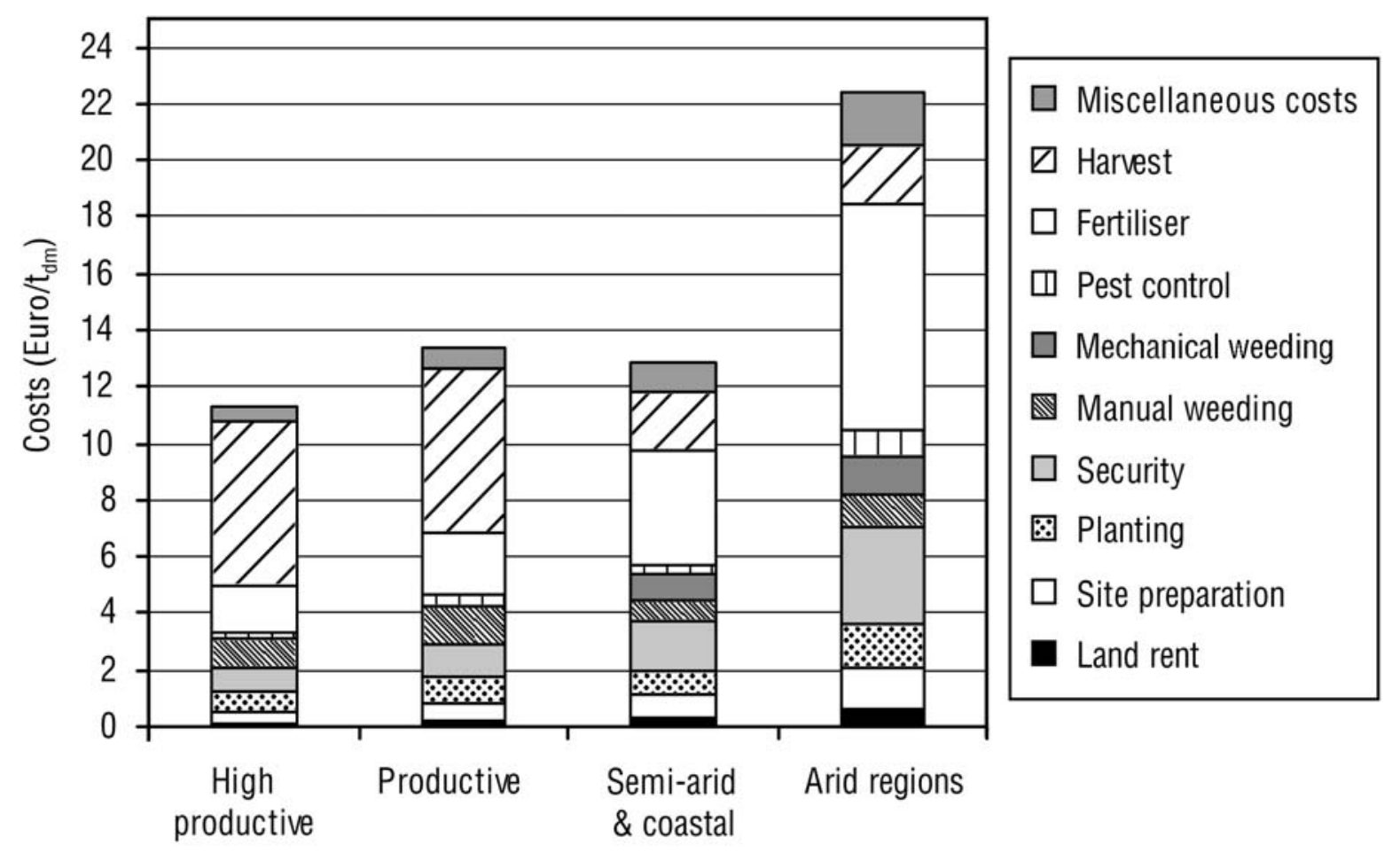

Figure 9. Comparison of bioenergy growing costs by region (Euro/tdm)

seven years in Mozambique. Up to four rotations are possible [Mangue, 2000]. We assume 4-year rotations for the productive regions, 7-year rotations for the semi-arid and coastal regions and 10-year rotation for the arid regions. To maintain continuous biomass supply we assume that for a production scheme with $\mathrm{n}$ years, the total area is divided into $\mathrm{n}$ plots, where one plot is planted in each successive year, with harvesting of the first plot being done in the $\mathrm{n}^{\text {th }}$ year.

We assume planting density of 2,500 trees/ha for the arid regions and 4,000 trees/ha for the productive regions $^{[16]}$. Unit seedling costs are estimated to be $\$ 0.02$ per plant. We also assume that Eucalyptus grandis is the selected species for the productive regions with high rainfall 


\section{Articles}

Table 7. Summary of biomass-growing costs

\begin{tabular}{|c|c|c|c|c|c|c|c|}
\hline Parameter & Value & Unit & $\begin{array}{c}\text { Note } \\
\text { reference }\end{array}$ & Parameter & Value & Unit & $\begin{array}{c}\text { Note } \\
\text { reference }\end{array}$ \\
\hline \multicolumn{4}{|l|}{ Financial data } & & & & \\
\hline Interest rate & 10 & $\%$ & [1] & Tractor, cultivation & 6.5 & $\$ / \mathrm{hr}$ & {$[8]$} \\
\hline Land rent & $0.6-2.5$ & $\$ /$ ha & [2] & Liquid pesticide & 2.8 & $\$ / 1$ & {$[8]$} \\
\hline Labour cost unskilled & 0.25 & $\$ / \mathrm{hr}$ & [3] & Removal of trunks & 1.8 & $\mathrm{hr} / \mathrm{ha}$ & {$[8]$} \\
\hline Labour cost skilled & 1.18 & $\$ / h r$ & [3] & Ploughing with tractor & 0.72 & $\mathrm{hr} / \mathrm{ha}$ & [8] \\
\hline Working days per year & $175-250$ & day/yr & [4] & Deep ploughing & 1.8 & $\mathrm{hr} / \mathrm{ha}$ & {$[8]$} \\
\hline Price of diesel & 15.2 & Euro/GJ & [5] & Levelling with tractor & 1.9 & $\mathrm{hr} / \mathrm{ha}$ & {$[8]$} \\
\hline Price of fuel oil & 7.9 & Euro/GJ & [5] & Transport of plants & 1.7 & $\mathrm{hr} / \mathrm{ha}$ & {$[8]$} \\
\hline Price of electricity & 13 & Euro/MWe & [5] & Planting time & 9.3 & $\mathrm{hr} / \mathrm{ha}$ & {$[8]$} \\
\hline \multicolumn{4}{|l|}{ General physical data } & Pesticide application & 1.7 & 1/ha & {$[8]$} \\
\hline Euacalyptus yield & $7-25$ & $\mathrm{t}_{\mathrm{dm}} / \mathrm{ha} / \mathrm{yr}$ & [6] & Pesticide application & 7.6 & day/ha & {$[8]$} \\
\hline Density plantations & $2500-4000$ & trees/ha & [7] & Roll of wire for fence & 0.17 & $\$ / \mathrm{m}$ & {$[8]$} \\
\hline HHV eucalyptus & 19.4 & $\mathrm{GJ} / \mathrm{t}_{\mathrm{dm}}$ & {$[8]$} & Construction of fence & 4 & day/ha & {$[8]$} \\
\hline M.c. at harvest & 50 & $\%$ & [9] & \multicolumn{4}{|l|}{ Plantation maintenance } \\
\hline M.c. dried in the field & 30 & $\%$ & {$[10]$} & Manual weeding & 2.9 & day/ha/turn & {$[8]$} \\
\hline Density of eucalyptus & 0.6 & $\mathrm{t}_{\mathrm{dm}} / \mathrm{m}^{3}$,solid & {$[8]$} & Tractor weeding & 2.4 & $\mathrm{hr} / \mathrm{ha} /$ turn & {$[8]$} \\
\hline LHV diesel & 42.7 & $\mathrm{MJ} / \mathrm{kg}$ & [8] & Fertiliser application & 1.5 & $\mathrm{hr} / \mathrm{ha}$ & {$[8]$} \\
\hline LHV fuel oil & 40.1 & $\mathrm{MJ} / \mathrm{kg}$ & {$[8]$} & Fertiliser application & 102 & $\mathrm{~kg} / \mathrm{ha} / \mathrm{yr}$ & [12] \\
\hline \multicolumn{4}{|l|}{ Establishment costs } & Fire control (labour) & 4 & days/ha/yr & {$[8]$} \\
\hline Plant cost & 0.02 & $\$ /$ plant & [11] & & & & \\
\hline Tractor, deep ploughing & 13 & $\$ / \mathrm{hr}$ & {$[8]$} & & & & \\
\hline Tractor, ploughing & 9.8 & $\$ / \mathrm{hr}$ & {$[8]$} & & & & \\
\hline Tractor, levelling & 12 & $\$ / h r$ & [8] & & & & \\
\hline
\end{tabular}

Notes

1. Source: BdM, 2005. Interest rates were deregulated in the mid-1990s and financial institutions charge different rates. The average inter-bank rate given by the central bank is about $11 \%$ and we project a future rate of $10 \%$ in this study.

2. The standard rate is $\$ 1.25 /$ ha, although for the establishment of large-scale plantations of over 1000 ha, land rent becomes $\$ 2.5 /$ ha [de Quadros, 2003].

3. Skilled workers are, e.g., drivers in the forestry sector [Fath, 2002].

4. Mozambican law allows year-round forestry operations in drier regions (estimate of 250 days) but limits it to about 175 days in humid areas [Cruz, 2004].

5. Public selling price from distributors in March 2005, general tariff for electricity [CPI, 2005].

6. Yields are generally related to agro-ecological potential, rainfall is the key determinant, practical limits are influenced by nutrient availability and sunlight. Marrison and Larson [1996] use the correlation (Yield $(\mathrm{tdm} / \mathrm{ha} / \mathrm{yr})=(0.016 \times$ precipitation) -1.05$)$. For Mozambique, theoretical maximum yield levels can be about 35tdm/ha/yr. Macucule [2001] gives average wood volume of $512 \mathrm{~m}^{3} / \mathrm{ha}$ at IFLOMA (Manica) which corresponds to about $26 \mathrm{t}$ dm/ha/yr. MMETZ [1998] gives yield estimates for eucalyptus of $25 \mathrm{t}_{\mathrm{dm}} / \mathrm{ha} / \mathrm{yr}$ for a neighbouring Zimbabwean study. Ugalde and Perez [2001] give ranges of eucalyptus mean annual increment (MAl) in Southern Africa of between 9 and $54 \mathrm{~m}^{3} / \mathrm{ha} / \mathrm{yr}$.

7. Arid soils cannot sustain plantation densities beyond 2500 trees/ha, higher densities are possible in more productive soils [Cruz, 2004].

8. Broek, 2000, p. 47

9. M.c.: moisture content of eucalyptus at harvest [Junginger et al., 2001]

10. Moisture content of eucalyptus after open-air drying in the field [Hamelinck et al., 2003]

11. Seedling costs in Southern Africa [Mabvurira and Pukkala, 2002]

12. Based on nutrient requirements from studies done in Congo [Laclau et al., 2003], about $102 \mathrm{~kg} / \mathrm{ha} / \mathrm{yr}$ of fertilisers are required in the following proportions: $\mathrm{N}$ (64), $\mathrm{P}$ (8) and $\mathrm{K}$ (30).

and rich soils, while Eucalyptus camaldulensis is the species of choice for the less productive arid areas ${ }^{[17]}$.

Table 7 summarises the main costs for the establishment and maintenance of eucalyptus plantations. The costs illustrate the contribution of labour, equipment (including investment and operational costs) and various inputs (such as fertiliser and pesticides).

Eucalyptus production costs vary from 11.3 to 22.4 Euro/ $\mathrm{t}_{\mathrm{dm}}(0.6-1.15 \mathrm{Euro} / \mathrm{GJ})$ in the highly productive and the arid regions respectively as shown in Figures 9 and
10. The effect of low biomass productivities in the production cost is evident for the arid regions ${ }^{[18]}$. Biomass costs for the semi-arid and coastal regions are $14 \%$ higher than in the highly productive regions but $4 \%$ lower than in the productive regions because the relatively lower productivity in the semi-arid regions is compensated by a longer discounting period (due to longer rotation periods). The highly productive and productive regions are assumed to have similar plantation management regimes but differ in biomass yield levels, explaining 


\section{Articles}

Table 8. Eucalyptus plantation establishment and maintenance cost item breakdown

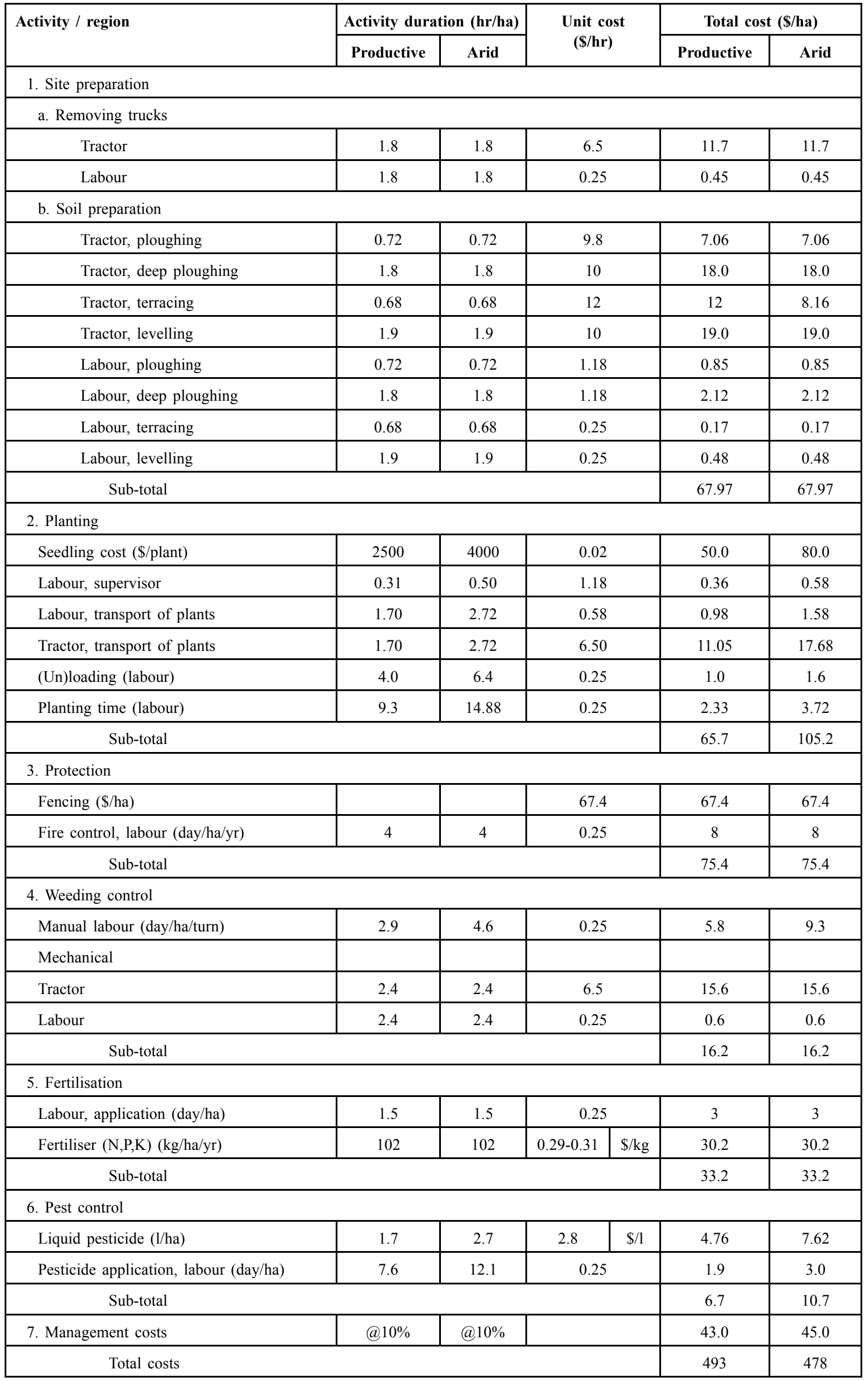




\section{Articles}

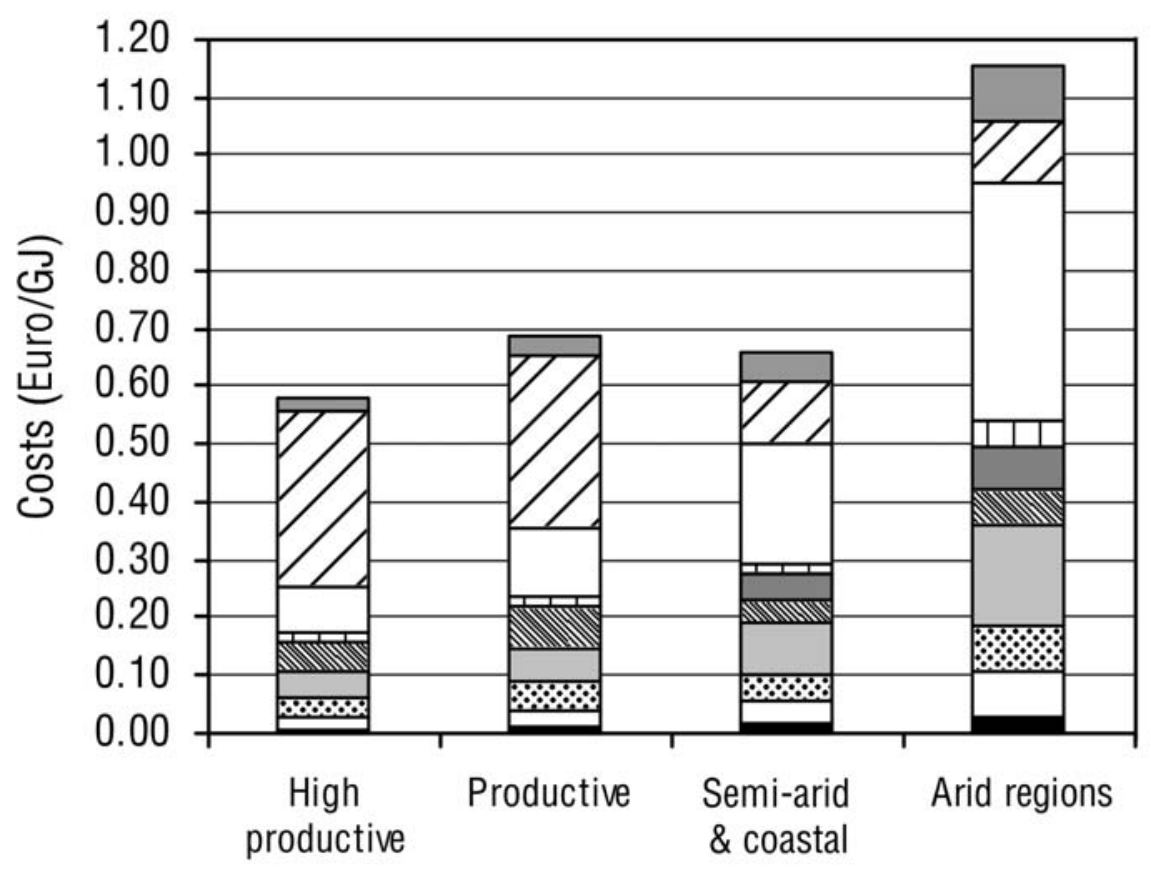

Miscellaneous costs

$\square$ Harvest

Fertiliser

प Pest control

Mechanical weeding

Manual weeding

Security

图 Planting

Site preparation

Land rent

Figure 10. Comparison of bioenergy growing costs by region (Euro/GJ)

Table 9. Selected bioenergy supply chains

\begin{tabular}{|c|c|c|c|c|c|c|c|c|c|c|}
\hline \multirow[t]{3}{*}{ Biofuel } & \multirow{3}{*}{$\begin{array}{l}\text { Location of } \\
\text { conversion } \\
\text { facility }\end{array}$} & \multicolumn{9}{|c|}{ Regions } \\
\hline & & \multirow[t]{2}{*}{ Niassa } & \multirow[t]{2}{*}{ Sofala } & \multirow[t]{2}{*}{ Zambézia } & \multicolumn{2}{|c|}{ Cabo Delgado } & \multicolumn{2}{|c|}{ Inhambane } & \multicolumn{2}{|c|}{ Gaza } \\
\hline & & & & & Inland CGP & Coastal CGP & Inland CGP & Coastal CGP & Water & Rail \\
\hline FT fuels & Central (CFB) & $\bullet$ & $\bullet$ & $\bullet$ & $\bullet$ & $\bullet$ & $\bullet$ & $\bullet$ & $\bullet$ & $\bullet$ \\
\hline \multirow[t]{2}{*}{ Pellets } & Local & $\bullet$ & $\bullet$ & $\bullet$ & $\bullet$ & & $\bullet$ & & $\bullet$ & $\bullet$ \\
\hline & Central & $\bullet$ & $\bullet$ & $\bullet$ & $\bullet$ & $\bullet$ & $\bullet$ & $\bullet$ & $\bullet$ & $\bullet$ \\
\hline \multirow[t]{2}{*}{ Pyrolysis oil } & Local & $\bullet$ & $\bullet$ & $\bullet$ & $\bullet$ & & $\bullet$ & & $\bullet$ & $\bullet$ \\
\hline & Central & $\bullet$ & $\bullet$ & $\bullet$ & $\bullet$ & $\bullet$ & $\bullet$ & $\bullet$ & $\bullet$ & $\bullet$ \\
\hline
\end{tabular}

the variation in unit energy costs.

Fertiliser, weeding and protection (against fire, browsers, e.g., cattle, deer, and theft) represent the highest cost component incurred in growing eucalyptus for all regions. (Figures 11a and 11b show the cost breakdown for growing biomass excluding harvesting operations.) In the productive regions, fertiliser accounts for up to $30 \%$ of overall costs while weeding and protection contribute about $19 \%$ and $15 \%$ respectively. Planting is also a major cost, accounting for $12 \%$, while site preparation represents $8 \%$ of the total costs.

In the arid regions fertiliser accounts for nearly $40 \%$ of the growing costs of eucalyptus, while security accounts for about $17 \%$.

\section{Bioenergy supply chain logistics}

The central focus of this study was to evaluate options for the delivery of biomass from production regions in Mozambique to international markets, here assumed to be delivery to Rotterdam harbour as a final destination.
Delivered biomass can be in the form of chips, pellets, bio-oils and fuels. Biomass supply logistics depends mainly on the biomass distribution density, operational scales, operating windows and relative distances to supply destinations. Figure 12 shows typical logistic stages for export of biomass. We focused on pre-treated biomass (i.e., pellets and pyrolysis oil) for long-distance transport because previous studies, [e.g., Hamelinck et al., 2003], showed that is better from the cost and energy points of view.

\subsection{Logistics concept}

Harvested biomass is collected at production sites and transported to a gathering point (GP) at a road or railway siding. (See Figure 13.) Trucks provide first transport ${ }^{[19]}$ to the GP while second transport to a central gathering point (CGP) is by truck or train. At the CGP, biomass undergoes pre-treatment, e.g., sizing, drying, densification but also conversion to liquid fuels like pyrolysis oil and FT fuels.

Some processes which are cost-effective at small scale 


\section{Articles}

Table 10. Operational data for biomass supply logistic steps

\begin{tabular}{|c|c|c|c|c|c|c|c|}
\hline Logistic operation & Base scale & Max scale & Base capital & O\&M & Scale factor & \multicolumn{2}{|c|}{ Energy-fuel } \\
\hline & $\left(\mathrm{m}^{3}\right.$ bulk $\left./ \mathrm{h}\right)$ & $\left(\mathrm{m}^{3}\right.$ bulk/h $)$ & (M Euro) & $\%$ & & \multicolumn{2}{|c|}{$(\mathrm{MJ} / \mathrm{t})$} \\
\hline \multicolumn{8}{|l|}{ Forest operations } \\
\hline Felling: manual & 23.9 & 23.9 & 0.008 & 100 & 1 & \multicolumn{2}{|c|}{7.9} \\
\hline Felling: harvest bundler & 53 & 53 & 0.075 & 10 & 1 & \multicolumn{2}{|c|}{39} \\
\hline Storage & $\left(\mathrm{m}^{3}\right)$ & $\left(\mathrm{m}^{3}\right)$ & (M Euro) & $\%$ & & \\
\hline Open-air pile (logs/bales) & 2 & 0 & 0 & 3 & 1 & \\
\hline Silo (chips/pellets) & 5000 & 5000 & 0.331 & 3 & 0.7 & \\
\hline Tank (conventional liquids) & 2272 & 2272 & 0.71 & 3 & 0.7 & \\
\hline Tank (unconventional liquids) & 2272 & 2272 & 0.811 & 3 & 0.7 & & \\
\hline Central sizing & $(\mathrm{t} / \mathrm{hr})$ & $(\mathrm{t} / \mathrm{hr})$ & (M Euro) & $\%$ & & \multicolumn{2}{|c|}{ Bond index $((\mathrm{kWh} . \sqrt{\mathrm{mm}}) / \mathrm{t})^{[4]}$} \\
\hline Roll crusher & 10 & 10 & 0.137 & 20 & 0.7 & \multicolumn{2}{|c|}{0.50} \\
\hline Hammer mill & 50 & 50 & 0.37 & 20 & 0.7 & \multicolumn{2}{|c|}{0.26} \\
\hline Bale chipper & 25 & 25 & 1.7 & 20 & 0.7 & \multicolumn{2}{|c|}{0.44} \\
\hline Chipper & 80 & 80 & 0.529 & 20 & 0.7 & \multicolumn{2}{|c|}{0.90} \\
\hline Pulverising & 8 & 100 & 0.282 & 20 & 0.7 & \multicolumn{2}{|c|}{0.348} \\
\hline Drying & $(\mathrm{t} / \mathrm{hr})$ & $(\mathrm{t} / \mathrm{hr})$ & (M Euro) & $\%$ & & $(\mathrm{kWh} / \mathrm{t})$ & $\begin{array}{l}\text { Fuel energy } \\
\left(\mathrm{GJ} / \mathrm{twe}^{[8]}\right)\end{array}$ \\
\hline Rotary drum (VandenBroek) & 100 & 100 & 5 & 3 & 0.7 & 20.00 & 2.50 \\
\hline Densification & $(\mathrm{t} / \mathrm{hr})$ & $(\mathrm{t} / \mathrm{hr})$ & (M Euro) & $\%$ & & $(\mathrm{kWh} / \mathrm{t})$ & \\
\hline Pellet press & 6 & 8 & 0.12 & 40 & 0.61 & 28.00 & \\
\hline Conversion & $\left(\mathrm{MW}_{\mathrm{th}, \mathrm{in}}\right)$ & $\left(\mathrm{MW}_{\mathrm{th}, \text { in }}\right)$ & (M Euro) & $\%$ & & $\left(\mathrm{kWh} / \mathrm{tdm}_{\mathrm{dm}}\right)$ & $\begin{array}{c}\text { Conversion } \\
\text { efficiency }\end{array}$ \\
\hline Pyrolysis & 1 & 10 & 0.1 & 4 & 0.62 & 37.20 & $67 \%$ \\
\hline Fischer-Tropsch $\left(\mathrm{EF}^{[6]}{ }_{\text {-pyrolysis }}\right)^{[3]}$ & 1000 & - & 41 & 4 & 0.5 & 23.60 & $71 \%$ \\
\hline Fischer-Tropsch (CFB-chips) ${ }^{[7]}$ & 387 & 400 & 110 & 4 & 0.78 & 34.50 & $40 \%$ \\
\hline Fischer-Tropsch (EF-pellets) ${ }^{[3]}$ & 1000 & - & 45 & 4 & 0.5 & 23.60 & $66 \%$ \\
\hline \multirow[t]{2}{*}{ Truck } & Capacity & Capacity & $\operatorname{Costs}^{[1]}$ & O\&M & Load/unload & Load unload & Energy use $^{[2]}$ \\
\hline & $(\mathrm{t})$ & $\left(\mathrm{m}^{3}\right)$ & (Euro/km) & $\%$ & $\left(\right.$ speed $\left(\mathrm{m}^{3} / \mathrm{hr}\right)$ & costs $\left(\right.$ Euro $\left./ \mathrm{m}^{3}\right)$ & $(\mathrm{MJ} / \mathrm{km})$ \\
\hline Truck-logs/bales & 28.00 & 100 & 1.12 & 4 & 260.00 & 0.5 & 18.20 \\
\hline Truck - pellets-briquettes & 28.00 & 100 & 1.12 & 4 & 260.00 & 0.5 & 18.20 \\
\hline Truck - fuels & 28.00 & 100 & 1.63 & 4 & 260.00 & 0.5 & 18.20 \\
\hline \multirow[t]{2}{*}{ Train } & Capacity & Capacity & Costs $^{[1]}$ & $\mathrm{O} \& \mathrm{M}^{[5]}$ & Load/unload & Load/unload & Energy use \\
\hline & $(\mathrm{t})$ & $\left(\mathrm{m}^{3}\right)$ & (Euro/km) & $\%$ & speed $\left(\mathrm{m}^{3} / \mathrm{hr}\right)$ & Costs $\left(\right.$ Euro $\left./ \mathrm{m}^{3}\right)$ & $(\mathrm{MJ} / \mathrm{km})$ \\
\hline Rail logs/bales & 1000 & 2500 & 7.00 & - & 240 & 0.23 & 326 \\
\hline Rail - pellets & 1000 & 2500 & 7.00 & - & 260 & 0.23 & 326 \\
\hline Rail - tank liquid fuels & 1000 & 2500 & 8.75 & - & 500 & 0.23 & 326 \\
\hline Rail - tank pyrolysis oil & 1000 & 2500 & 9.98 & - & 500 & 0.23 & 326 \\
\hline \multirow[t]{2}{*}{ Ship } & Capacity & Capacity & Investment & O\&M & Charter costs & Other charges & Energy use \\
\hline & $(\mathrm{t})$ & $\left(\mathrm{m}^{3}\right)$ & (M Euro) & $\%$ & (Euro/day) & (Euro/trip) & $(\mathrm{MJ} / \mathrm{km})$ \\
\hline CVI-small bulk carrier & 4000 & 6667 & 11.35 & 10 & 0 & $14^{[1]}$ & 647 \\
\hline Suezmax bulk carrier & 150,000 & 250,000 & 42.26 & 8 & 17,723 & 180,000 & 4516 \\
\hline Suezmax tanker & 125,000 & 143,678 & 43.05 & 10 & 14,778 & 150,000 & 3763 \\
\hline CVI - small fuels & 4000 & 6667 & 11.35 & 10 & 0 & $14^{[1]}$ & 647 \\
\hline
\end{tabular}

Source: [Hamelinck et al., 2003] except where indicated.

\section{Notes}

1. Generally, long-distance truck transportation of goods in Mozambique costs between $\$ 0.03$ and $0.05 / \mathrm{t} . \mathrm{km}$. Costs of shipping large quantities of goods (1500 t) within domestic ports are about $\$ 0.03 / \mathrm{t} . \mathrm{km}$. Unloading and loading ships costs about $\$ 11 / \mathrm{t}$ while port charges are about $\$ 14 / \mathrm{t}$. Short-distance transportation charges, such as for transport from field to railhead, are about $\$ 10 /$ t. Rail charges are estimated to be about $\$ 0.016 /$ t.km [Jeje et al., 1998].

2. A 350 -hp $(1 \mathrm{hp}=746 \mathrm{~W})$ truck used for forestry operations consumes on average 27 I of diesel per hour [Fath, 2002]. We assume diesel locomotives consume about $326 \mathrm{MJ} / \mathrm{km}$. The Suezmax bulk carrier and tanker use about $4500 \mathrm{MJ} / \mathrm{km}$ and $3760 \mathrm{MJ} / \mathrm{km}$ respectively. According to Hamelinck et al. [2003], fuel use by ships depends upon the ship's size and speed and a data fit for several ships provides a generalised representation which can be used for other ship sizes.

3. See [Calis et al., 2003] for more details.

4. A commonly-used energy law for size reduction is the Bond law: $E=100 \times E_{i} \times(1 / \sqrt{ } x P-1 / \sqrt{ } x F)$, when the energy consumption $E$ for a given size reduction $x F \rightarrow x P$ is known, the Bond work index $\mathrm{E}_{\mathrm{i}}$ can be calculated and used for other product sizes. For dry grinding the index must be increased by a factor of 1.34 over that measured in wet grinding [Hamelinck et al., 2003].

5. Where annual costs represent investment costs, the capital and O\&M costs are recalculated from the km costs, (un)load charges + other charges.

6. Pressurised oxygen-blown entrained flow gasification using pyrolysis oil and pulverised pellets as input

7. Direct pressurised oxygen-blown circulating fluidised bed gasifier using pulverised raw biomass as input

8. $\quad$ twe $=$ tonnes of water evaporated 


\section{Articles}

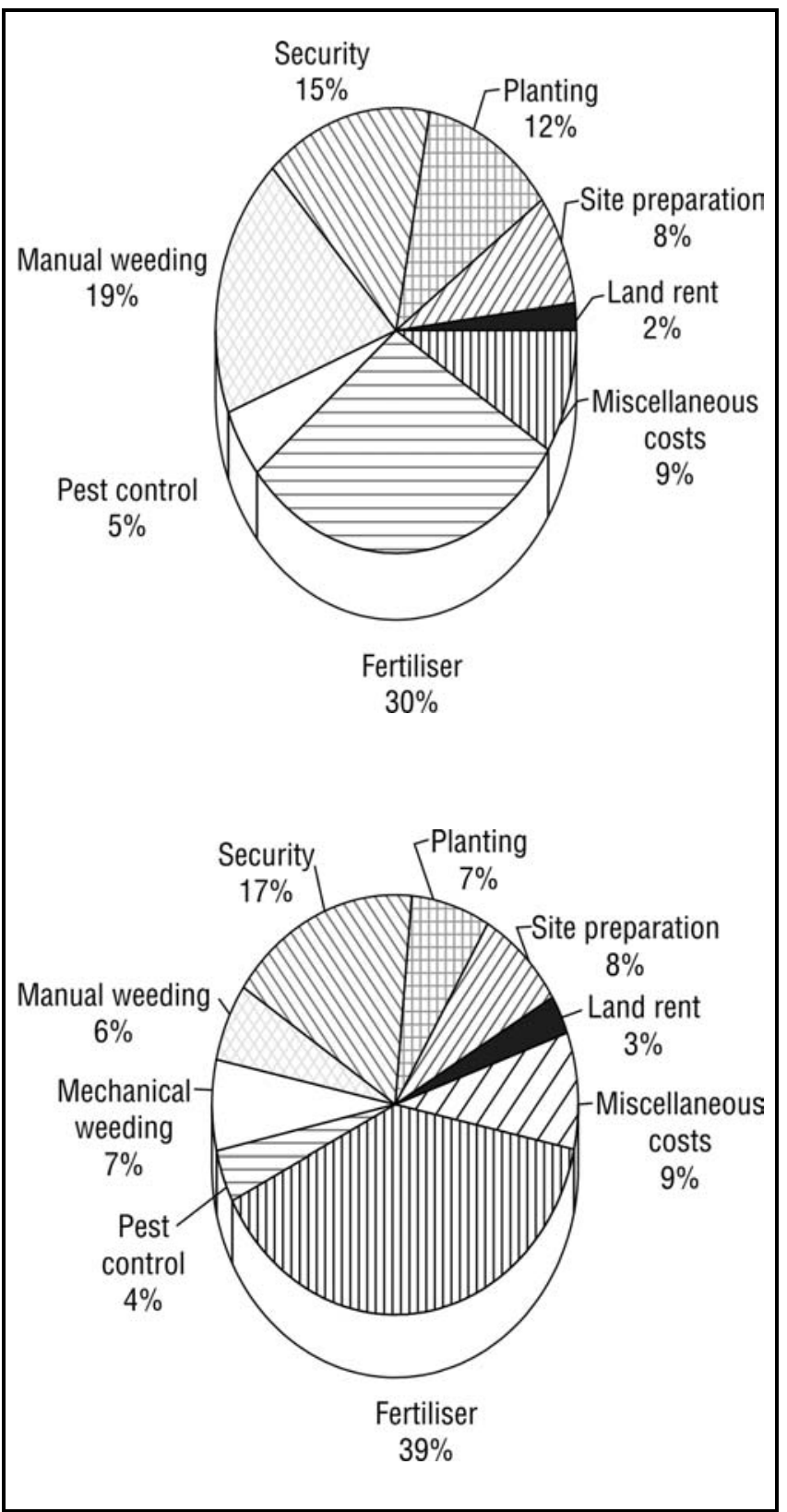

Figure 11. Breakdown of costs for eucalyptus plantation growing: (a) in productive regions (total cost $=0.28$ Euro/GJ); $(b)$ in arid regions (Total costs $=1.04$ Euro/GJ)

may be carried out locally, but generally capital-intensive conversion processes benefit from scaling effects and are therefore located centrally.

Some 42 chains were selected and analysed to determine the most cost-effective supply chain for biomass fuels from Mozambique to Rotterdam as shown in Table 9. The chains were selected on the basis of four main criteria:

- differentiated biomass productivity for the three macro-agro-ecological zones (productive, semi-arid and coastal, arid);

- biomass pre-treatment technology defined by the delivered bio-fuel (pellets, pyrolysis oil and FT fuels);

- location of conversion facility (local, central) - early conversion reduces "downstream" logistic capacity, while centralised production benefits from technological scale effects; and
- maximisation of the use of rail and water transport for longer-distance transportation where possible.

The bioenergy supply chains are characterised by the commodities undergoing international transport, i.e., pellets, pyrolysis oil or FT fuels, as well as the biomass production areas, e.g., Niassa (productive), Sofala (arid). There are five basic chains for each region representing localised and centralised production.

\subsection{Logistics operations}

The biomass logistics model developed by Hamelinck et al. [2003] was used to analyse and optimize bioenergy supply chains as shown in Figure 12. Most of the default operational data in the model was used in the analysis but we highlight the assumptions made for Mozambique.

Due to the different conditions in the humid and dry regions, operating windows ${ }^{[20]}$ are dissimilar. It is assumed that forestry operations are possible for 250 days in drier zones but limited to about 175 days in the humid areas [Cruz, 2004; Broek, 2000]. In addition, harvesting technologies are different. We assume the use of harvest bundlers in the humid regions: due to the shorter rotation period and dense planting, harvested tree stems are thinner and closer together than in the arid regions. It is therefore more efficient to use a single machine which cuts and bundles the stems ready for transportation. For the other regions with longer rotations and consequently larger trees, we assume conventional motor-manual harvesting techniques to be employed ${ }^{[21]}$.

The harvested biomass is stored in the field for up to six weeks to facilitate natural and low-cost drying (to about $30 \%$ moisture content). The costs of open-air storage in the field would be equivalent to the land costs or opportunity cost of land. For Mozambique, these costs are small and hence ignored. Further storage occurs at other transfer points in the chain. (See Figure 12.)

Further processing requires that raw biomass in the form of logs or bundles ( $\sim 3000 \mathrm{~mm}$ particle size) be comminuted to specific feedstock particle sizes, e.g., chips $(\sim 30 \mathrm{~mm})$. For achieving a $30 \mathrm{~mm}$ particle size, we assume use of a roll crusher for logs and a bale chipper for bales. Pelletising and pyrolysis conversion require a feedstock size of less than $10 \mathrm{~mm}$ and a hammer mill is then used to grind the $30 \mathrm{~mm}$ particles to below $10 \mathrm{~mm}$.

Conversion processes have strict requirements for moisture content ${ }^{[22]}$ of biomass feedstock and the rotary drum drier (direct contact type) is assumed to be the drying technology in this study [Hamelinck et al., 2003]. See Table 10 for more operational data.

We assume the pellet press is used for pelletising while pyrolysis conversion is done via flash pyrolysis. Technical specifications are given in Table 10.

Conversion of FT fuels is via direct pressurised oxygen blown circulating fluidised bed (CFB) gasification technology fed with chips. We also make a simple comparison of FT fuel production via pressurised oxygen-blown entrained flow (EF) gasification using pyrolysis oil and pulverised pellets as input.

CFB gasification has the disadvantage that it has limited 


\section{Articles}

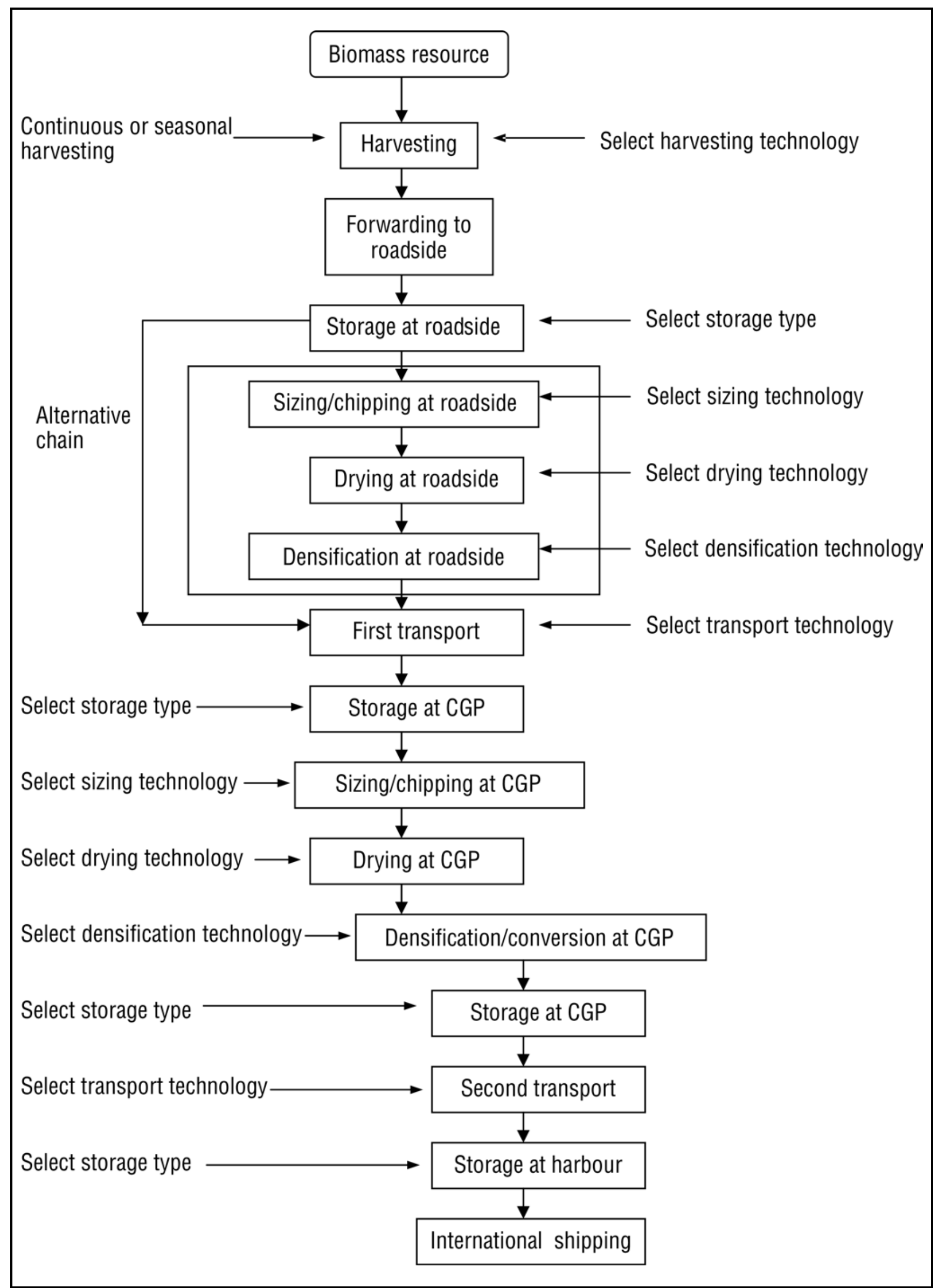

Figure 12. Procedure for using the logistics model [adapted from Hamelinck et al., 2003] 


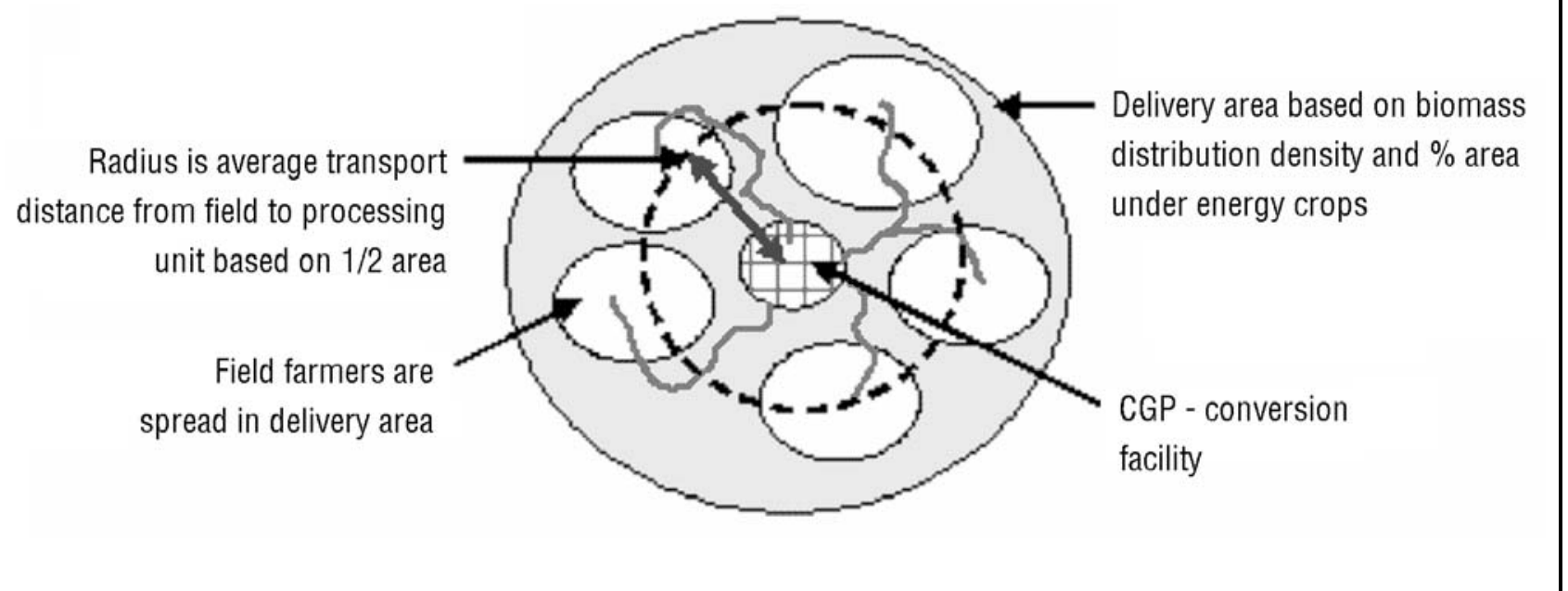

Figure 13. Theoretical representation of local biomass logistics

maximum capacity of about $400 \mathrm{MW}_{\text {th }}$ for a single unit whereas EF gasification units in the $1000 \mathrm{MW}_{\text {th }}$ range are possible. This allows greater scaling benefits for EF gasification (costs for $1000 \mathrm{MW}_{\text {th }}$ unit are about 41-45 million Euro (M Euro) compared to about $110 \mathrm{M}$ Euro for a 387 $\mathrm{MW}_{\text {th }}$ CFB plant ${ }^{[23]}$ ) [Hamelinck, 2004; Calis et al., 2003].

EF gasification is designed for use with coal and heavy oil and difficult to feed with chips. It is therefore more appropriate to use pulverised biomass or pyrolysis oil as feedstock for EF gasification. However, EF gasification is inappropriate for use in the field due to the scale of operation and is best suited for centralised production at, e.g., harbours. The main drawback of the EF route is the long-distance transportation of biomass to the conversion facilities.

\subsection{Biomass transportation}

Biomass is transported from the field to a local GP, from where it is further transported to the CGP (as explained in Section 7.1). After pre-treatment, the biomass is transferred to the harbour for international shipping. To estimate transportation distances, we represent farming areas as circles with a uniform biomass distribution density. The biomass distribution density depends on the percentage of land under crops and the biomass yields. We assume in this study a base percentage of $10 \%$ of land under energy crops in each region. The area of the circle represents the total biomass delivery area to provide sufficient feedstock for a central biomass processing unit. The biomass processing unit (with a specific processing capacity) is located at the centre of this circle as shown in Figure 11. Transport distance from the field to the processing unit is given as the radius of the circle. It is estimated on the basis of the "delivery area" around the pre-treatment plant, coverage of the energy crop $(\mathrm{C}$, as \% of total area), crop yields ( $\mathrm{Y}$ in $\mathrm{t} / \mathrm{km}^{2}$ ) and plant capacity $(\mathrm{P}$ in $\mathrm{t} / \mathrm{yr}$ ) as follows:

$$
R=\sqrt{\left(\frac{P}{2 \cdot \pi \cdot Y \cdot C}\right)}
$$

In all cases, the provincial capitals were selected as the CGP for biomass collection and processing (see map in Figure 7). The main transportation modes in the inland interior are road and rail. Water transportation is also possible along the coast where transfers are required to ports with facilities for sea-going ships. International shipping is considered to take place using the Suezmax bulk carriers $(120,000-200,000 \mathrm{t})^{[24]}$. Rotterdam harbour in the Netherlands was selected as a typical destination (import) port to enable comparison of international shipping costs from the six regions of Mozambique. Distances from Mozambican ports of Maputo, Beira and Nacala to Rotterdam are estimated to be $12,000,10,800$ and $9600 \mathrm{~km}$ respectively.

Regional first, second and port transfer distances are given in Table 11. Cabo Delgado and Inhambane have no rail links and raw biomass (logs and bundles) has to be transported over long distances by truck. A second scenario uses an interior CGP to reduce the truck transport of raw biomass.

In Gaza province, both water and rail transport options for transfer to Maputo were explored. Figure 8 shows the supply routes for the various regions including the selected production sites.

\section{Results of supply chain analysis}

The logistics analysis compares and shows the range of biofuel costs delivered from each selected region in Mozambique to Rotterdam harbour for pellets, pyrolysis oil and FT fuels. A summary of the results is shown in Table 12. It also compares energy use and $\mathrm{CO}_{2}$ emissions for the supply chains considered. In addition, we compare the three biofuel forms by using FT fuel as a reference energy form to which both pellets and pyrolysis oil are converted at the importing harbour (Rotterdam) and compare them with FT fuels supplied directly from Mozambique.

Pellets can be delivered in Rotterdam at as low as 50 Euro/ $t_{\mathrm{dm}}$ or $2.6 \mathrm{Euro} / \mathrm{GJ}$ while pyrolysis oil can be delivered at about 3.2 Euro/GJ. Similarly, FT fuels processed 


\section{Articles}

Table 11. Regional features

\begin{tabular}{|c|c|c|c|c|c|}
\hline \multicolumn{2}{|l|}{ Region } & $\begin{array}{l}\text { 1st transport } \\
\text { distance }(\mathrm{km})\end{array}$ & $\begin{array}{l}\text { 2nd transport } \\
\text { distance }(\mathbf{k m})\end{array}$ & $\begin{array}{l}\text { Centralised } \\
\text { transport (km) }\end{array}$ & Port \\
\hline \multicolumn{2}{|c|}{ Chain capacity (Mt/yr) } & 15.4 & $7-15.1$ & $1-6.6$ & \\
\hline \multicolumn{2}{|l|}{ Niassa } & 11.7 & 85.5 (truck) & 795 (rail) & Nacala \\
\hline \multicolumn{2}{|l|}{ Sofala } & 11.5 & 204.5 (rail) & - & Beira \\
\hline \multicolumn{2}{|l|}{ Zambézia } & 19 & 50.7 (ship) & 620 (ship) & Nacala \\
\hline \multirow[t]{2}{*}{ Cabo Delgado } & Option A & 13 & 173 (truck) & 148 (ship) & Nacala \\
\hline & Option B & 13 & 71 (truck) & 105 (truck) +148 (ship) & Nacala \\
\hline \multirow[t]{2}{*}{ Inhambane } & Option A & 16.6 & 204 (truck) & 470 (ship) & Maputo \\
\hline & Option B & 16.6 & 100 (truck) & 191 (truck) + 470 (ship) & Maputo \\
\hline \multirow[t]{2}{*}{ Gaza } & Option A & 15 & 76.5 (truck) & 274 (ship) & Maputo \\
\hline & Option B & 15 & 33.5 (truck) & 174 (rail) & Maputo \\
\hline
\end{tabular}

Table 12. Summary of supply chain characteristics by delivered fuel

\begin{tabular}{|c|c|c|c|c|}
\hline \multirow[t]{2}{*}{ Parameter } & \multirow[t]{2}{*}{ Fuel type } & \multicolumn{3}{|c|}{ Conversion type } \\
\hline & & Local & Central & EF \\
\hline \multicolumn{5}{|c|}{ Delivered cost } \\
\hline & Pellets (Euro/GJ) & $2.6-4.6$ & $2.8-5.6$ & - \\
\hline & Pyrolysis (Euro/GJ) & $3.2-5.7$ & $3.5-7.0$ & - \\
\hline & FT (Euro/GJ) & - & $6.8-10.8$ & 6.4 \\
\hline \multicolumn{5}{|c|}{ Energy use (input) } \\
\hline & Pellets $\left(\mathrm{GJ}_{\text {primary }} / \mathrm{GJ}_{\text {delivered }}\right)$ & $0.06-0.08$ & $0.06-0.1$ & - \\
\hline & Pyrolysis $\left(\mathrm{GJ}_{\text {primary }} / \mathrm{GJ}_{\text {delivered }}\right)$ & $0.07-0.1$ & $0.08-0.14$ & - \\
\hline & FT $\left(\mathrm{GJ}_{\text {primary }} / \mathrm{GJ}_{\text {delivered }}\right)$ & - & $0.1-0.19$ & 0.13 \\
\hline \multicolumn{5}{|c|}{ Energy requirement for energy } \\
\hline & Pellets (GJ $\left.\mathrm{primary} / \mathrm{GJ}_{\text {delivered }}\right)$ & $1.6-1.77$ & $1.65-1.78$ & - \\
\hline & Pyrolysis $\left(\mathrm{GJ}_{\text {primary }} / \mathrm{GJ}_{\text {delivered }}\right)$ & $2.63-2.73$ & $2.71-2.78$ & - \\
\hline & FT $\left(\mathrm{GJ}_{\text {primary }} / \mathrm{GJ}_{\text {delivered }}\right)$ & - & $5.24-5.35$ & 3.92 \\
\hline \multicolumn{5}{|c|}{$\mathrm{CO}_{2}$ emissions } \\
\hline & Pellets $\left(\mathrm{kg} \mathrm{CO}{ }_{2} / \mathrm{GJ}_{\text {delivered }}\right)$ & $1.9-3.4$ & $2.2-4.7$ & - \\
\hline & Pyrolysis $\left(\mathrm{kg} \mathrm{CO} 2 / \mathrm{GJ}_{\text {delivered }}\right)$ & $2.0-3.7$ & $2.3-5.0$ & - \\
\hline & FT $\left(\mathrm{kg} \mathrm{CO} / \mathrm{GJ}_{\text {delivered }}\right)$ & - & $1.8-4.7$ & 3.7 \\
\hline
\end{tabular}

via CFB gasification can be delivered at 6.8 Euro/GJ whereas from EF gasification at larger scales (1000 $\left.\mathrm{MW}_{\text {th,in }}\right)$ the final cost is 6.4 Euro/GJ. With an initial biomass amount ${ }^{[25]}$ of $131 \mathrm{PJ}$, fuel delivered in Rotterdam is about 116-123 PJ of pellets, 86-88 PJ of pyrolysis oil and $50-51 \mathrm{PJ}$ of FT fuels. The ranges reflect the differences in efficiencies of the chains, regional differences as well as matter losses especially in storage. Key cost differences between the regions are caused by different costs of biomass, harvesting methods, storage needs and trans- portation. Other logistics such as sizing, drying and conversion are identical since similar biomass amounts are fed into the chains.

Energy requirements for energy ${ }^{[26]}$ (including process energy input, conversion and distribution losses) are lower (1.6 to $1.78 \mathrm{GJ}_{\text {primary }} / \mathrm{GJ}_{\text {delivered }}$ ) for pellet chains, 2.63$2.78 \mathrm{GJ}_{\text {primary }} / \mathrm{GJ}_{\text {delivered }}$ for pyrolysis chains and much higher (5.24-5.35 GJ $\mathrm{J}_{\text {primary }} / \mathrm{GJ}_{\text {delivered }}$ ) for FT fuel chains. This is much higher than fossil fuel energy requirement for energy which ranges from 1.05 to 1.19 . When only 


\section{Articles}

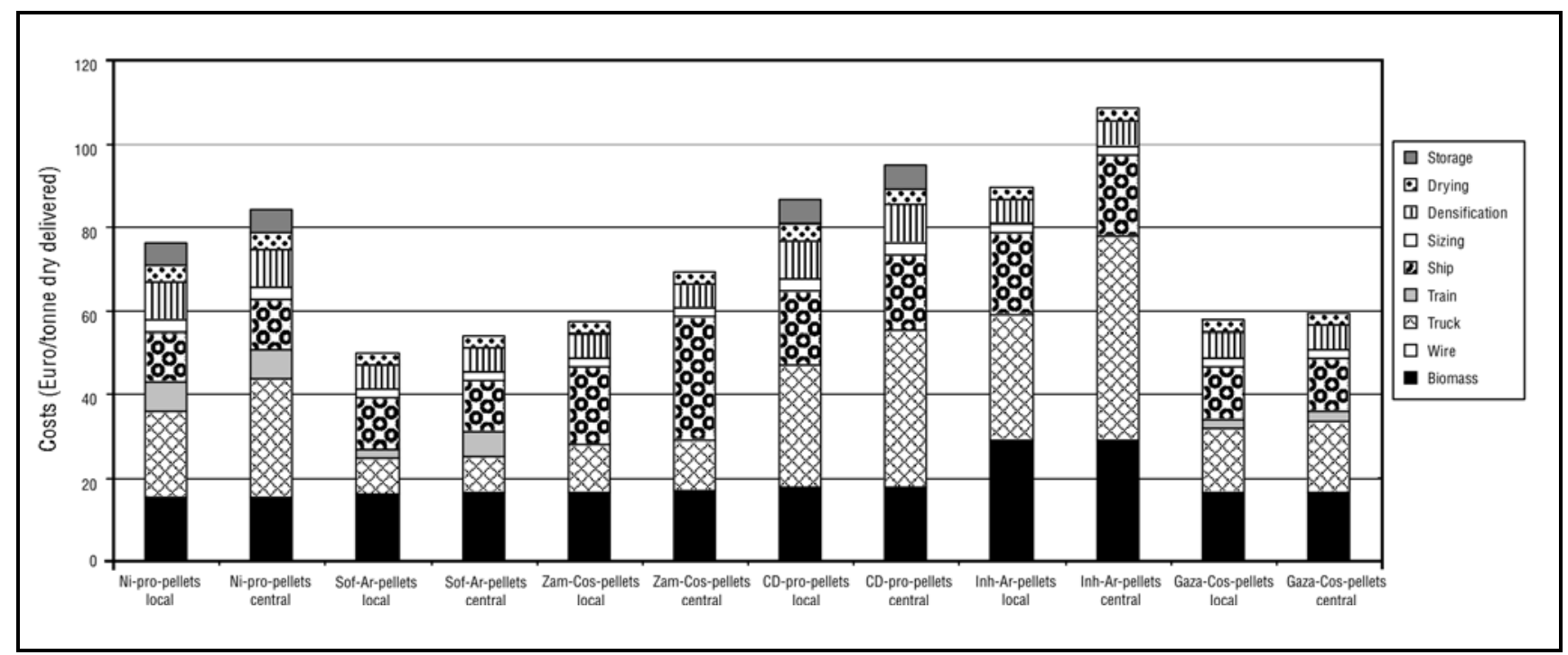

Figure 14. Chains supplying pellets to Rotterdam

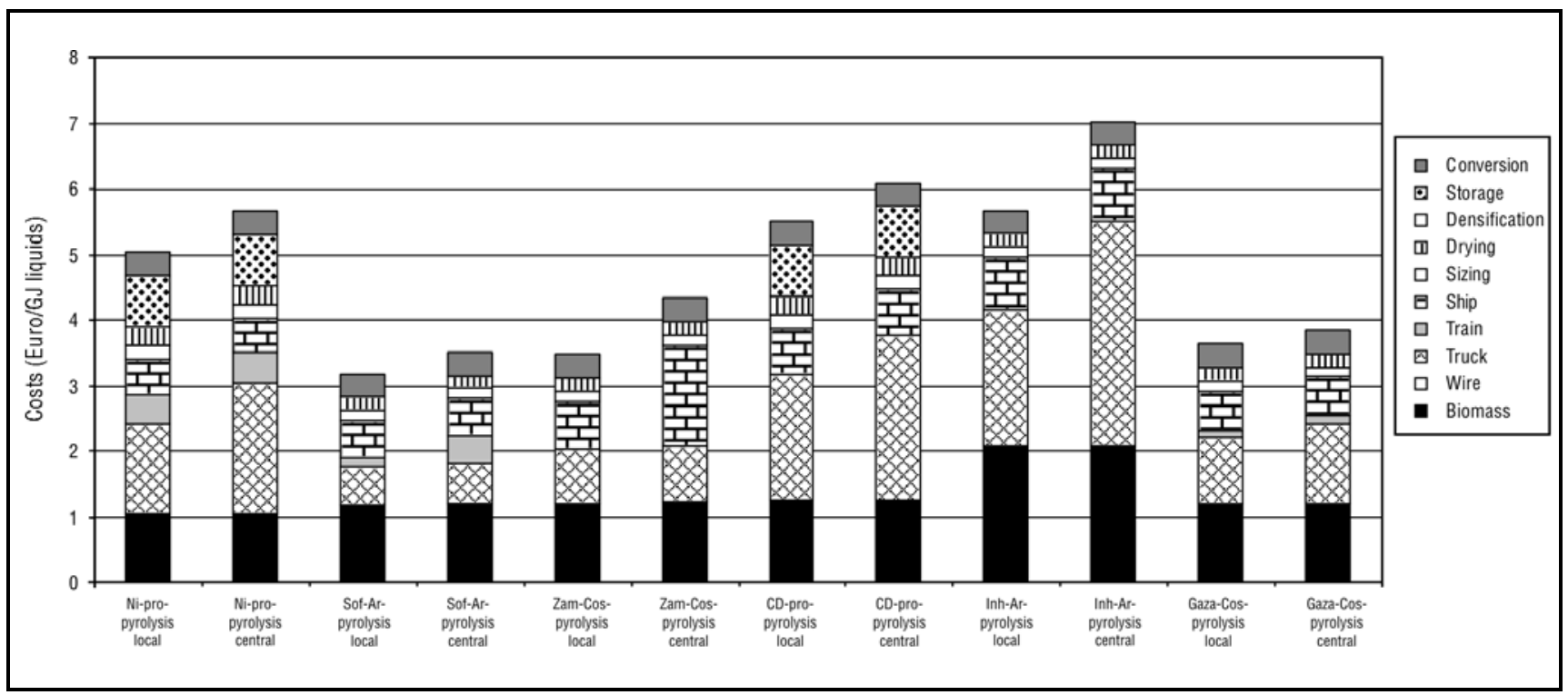

Figure 15. Chains supplying pyrolysis oil to Rotterdam

process energy input (especially diesel) requirements are considered, energy requirements are estimated to be 6$10 \%$ of delivered biomass (HHV) for pellet supply. This is lower than energy use for delivering pyrolysis oil (7$14 \%$ ) and FT fuels (10-19\%).

The ranges of $\mathrm{CO}_{2}$ emissions are similar for pellet chains and pyrolysis chains (2-5 $\left.\mathrm{kg} \mathrm{CO} / \mathrm{GJ}_{\text {delivered }}\right)$ while emissions from FT supply vary from 1.8 to $4.7 \mathrm{~kg}$

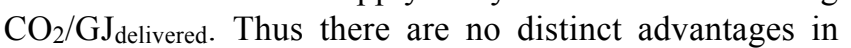
emission reduction among the technologies.

Pellets are delivered in Western Europe at a cost of between 2.6 and 5.6 Euro/GJ. Locally-produced pellets are cheaper than centrally-produced pellets in all regions, as shown in Figure 14. The cost of locally-produced pellets ranges from 2.6 to 4.6 Euro/GJ while that of centrally-produced pellets varies from 2.8 to 5.6 Euro/GJ. The semi-arid region of Sofala provides the cheapest source of pellets at 2.6 Euro/GJ while the arid region of Inhambane delivers the most expensive pellets at 5.6 Euro/GJ.
The cost of pyrolysis oil delivered in Rotterdam ranges from 3.2 to 7 Euro/GJ. The semi-arid region of Sofala is also the cheapest source of pyrolysis oil while the arid region of Inhambane is the most expensive (see Figure 15). Similar to pellets, chains supplying local pyrolysis achieve lower costs (3.2 to 5.7 Euro/GJ) compared to central production chains (3.5 to 7 Euro/GJ).

The cost of FT fuel production is significantly reduced when done at large centralised facilities $\left(\mathrm{GW}_{\text {th,in }}\right)$. For FT production via CFB gasification, delivered fuel costs range from 6.8 to 10.8 Euro/GJ with the cheapest source being Sofala and the most expensive being Inhambane (Figure 16). Delivered costs for FT fuels via EF gasification for a $1 \mathrm{GW}_{\text {th }}$ plant at Nacala port are about 6.4 Euro/GJ.

Logistic costs are mainly dictated by the first and second truck transport step. This second transport step is especially important if unprocessed biomass is being transported to a central facility. This results in costs for 


\section{Articles}

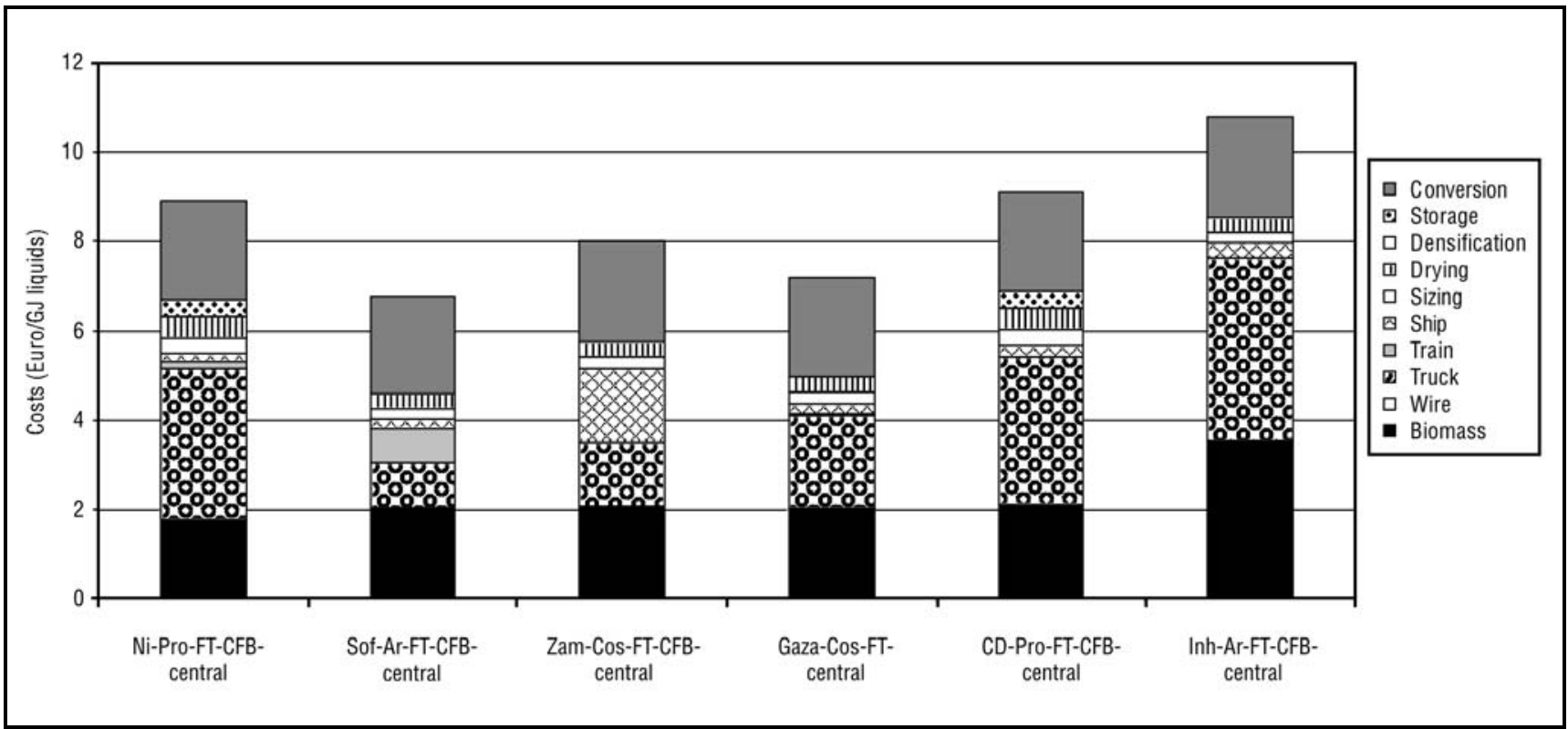

Figure 16. Chains supplying FT fuels to Rotterdam

centralised biomass conversion to be 13 to $24 \%$ higher than supply from local conversion. This is especially evident for the arid region of Inhambane, which requires long truck transport distances to the CGP. A solution to this problem would be to locate the CGP at a more central site and transport more compact biomass. However, the benefits of economies of scale intended by centralised production do not offset the higher transportation cost to the CGP. Reduction of logistical capacity ${ }^{[27]}$ earlier in the chain is therefore crucial for achieving lower delivered biomass costs, particularly for those regions which have no rail infrastructure. There are no scaling benefits arising from central processing, mainly because conversion technologies reach their maximum capacities with small amounts of biomass and multiple units have to be used, as higher scales achieve no further benefits. This is not the case however with FT fuel conversion, in which large benefits can be derived by centralised large-scale production. FT conversion contributes $20-33 \%$ to the overall fuel cost and is thus very sensitive to cost of capital and interest rates. This is also true for the other technologies but it is more significant for FT fuels.

Truck transport is the major contributor to high energy use in central production, accounting for up to $42 \%$ of overall energy use. Higher energy use due to long-distance transportation outweighs benefits of local production, as local chains supplied by interior regions result in higher costs compared to central production chains in coastal areas. Between 61 and $71 \%$ of the energy use is for transportation fuel. Since transportation is the most important energy user, it is important to find the most efficient form of transportation for inland regions distant from the exporting harbour.

Rail and water transport have significant efficiency and cost reduction benefits as those regions which have a rail service achieve much lower inland transportation costs. Coastal areas have cost advantages compared to regions in the interior, although the absence of sea-going ports requires additional costly transportation by smaller vessels.

Across the regions considered, international shipping costs vary (e.g., for southern provinces costs are 1.3 Euro/t more), but this does not affect the final cost of biomass significantly as lower costs are still achieved by supply from the south.

Lower biomass production costs are not decisive in delivered energy costs as they fail to compensate for the higher transportation costs from the inland productive regions. While the volumes may be important for supply from the productive regions, biomass costs are not important for the overall costs.

Biofuel costs are mostly sensitive to variation in yield levels, operating window and interest rate changes as shown in Figures 17, 18 and $19^{[28]}$. An increase in biomass yields results in reduced biomass cost and correspondingly shorter first truck transport distances. The opposite is also true. A decrease of the operating window (e.g., from 8 to 6 months) results in higher delivered fuel costs due to the low load factor of expensive equipment and longer storage periods. Changes in interest rates directly affect the cost of capital investment in the equipment and result in fuel cost variation of about $34 \%$ for pellets, $38 \%$ for pyrolysis oil and $42 \%$ for FT fuel chains.

Varying the percentage of land under energy crops and ship sizes does not have a significant impact on the final fuel cost.

Pellet chains are more energy-efficient compared to liquid fuel chains; about 116-123 PJ (or 76-79 \% of the original energy value of the biomass on a HHV basis) is delivered at the final destination while pyrolysis delivers about $55 \%$ of the original biomass energy. For pellets, about $13 \%$ of the biomass is lost during conversion and distribution while $8-11 \%$ is used as fuel during drying. The energy losses during conversion of pyrolysis (33\%) and FT fuels $(60 \%)$ are therefore more important in the 


\section{Articles}

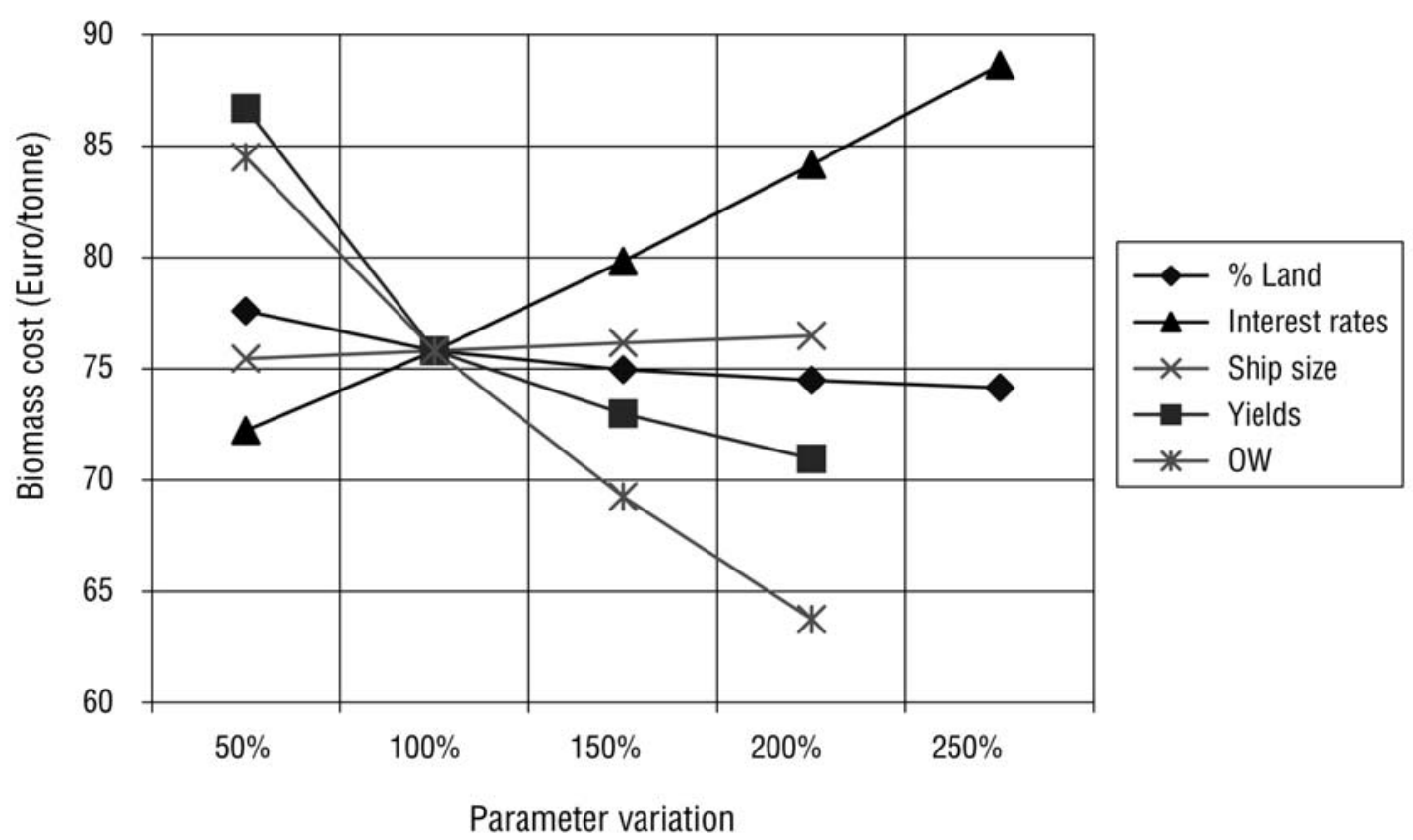

Figure 17. Sensitivity analysis of pellet costs

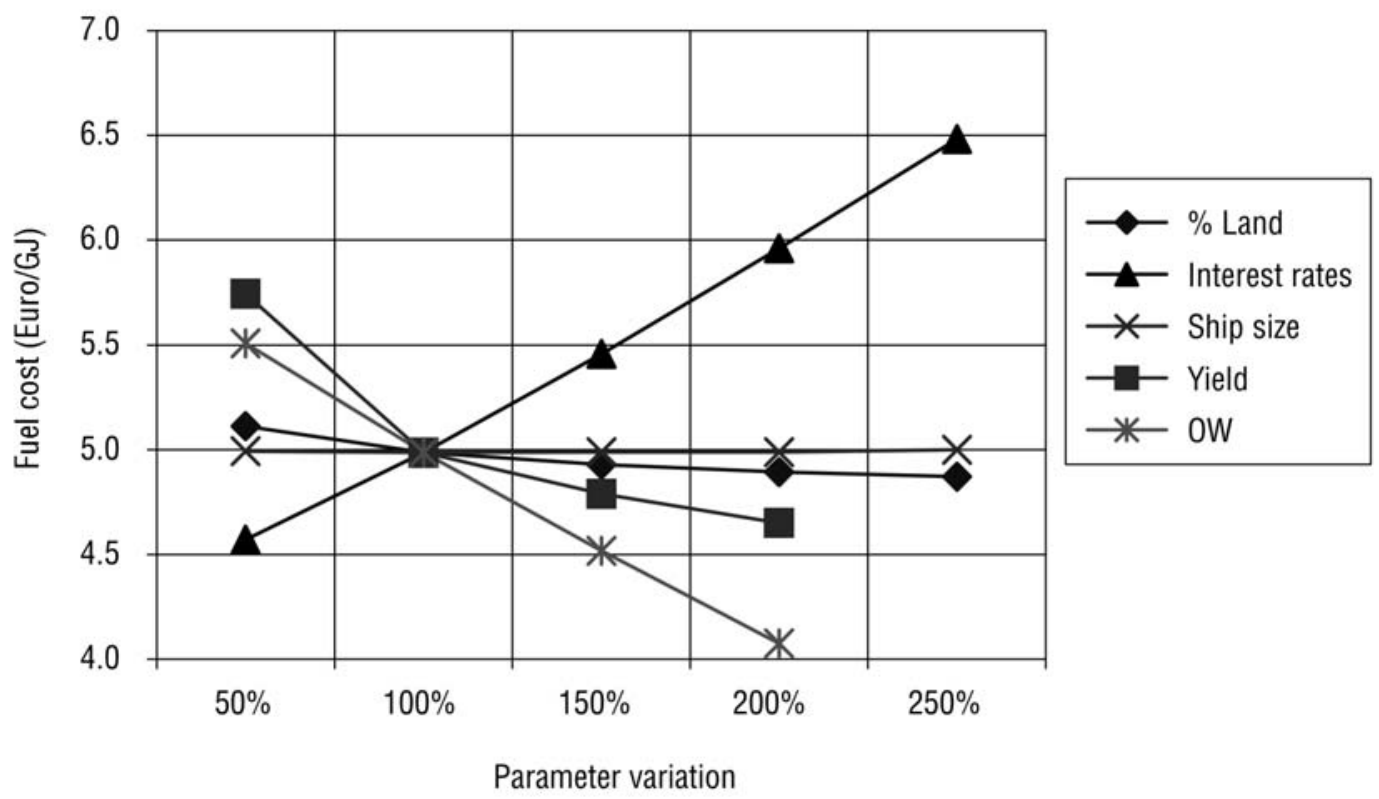

Figure 18. Sensitivity analysis of pyrolysis oil costs

final energy unit cost than the gains from transporting denser biomass.

The major differences between chains supplying pellets and pyrolysis oils are encountered in the post-drying steps where pellet conversion and transportation costs are higher. This is to be expected since scaling advantages are limited for pelletising technology and the transportation of bulkier pellets is more expensive. Handling of pyrolysis oil is also easier. For example, loading/unloading rates of $1200 \mathrm{t} / \mathrm{hr}$ can be achieved compared to pellets of between 100 and 1000 t/hr [Hamelinck et al., 2003].
Pellets also require more international shipping trips than the liquid fuels, resulting in higher costs for this step. The extra costs of transportation and storage ${ }^{[29]}$ needed for transporting pyrolysis oil are not significant in the overall annual costs when compared to the extra costs associated with bulkier pellet-type material (see Figure 20 for the contribution of different cost factors for the different supply chains).

8.1. Comparison of FT fuel conversion via EF and CFB gasification

We used FT fuel as a reference energy form to which both 


\section{Articles}

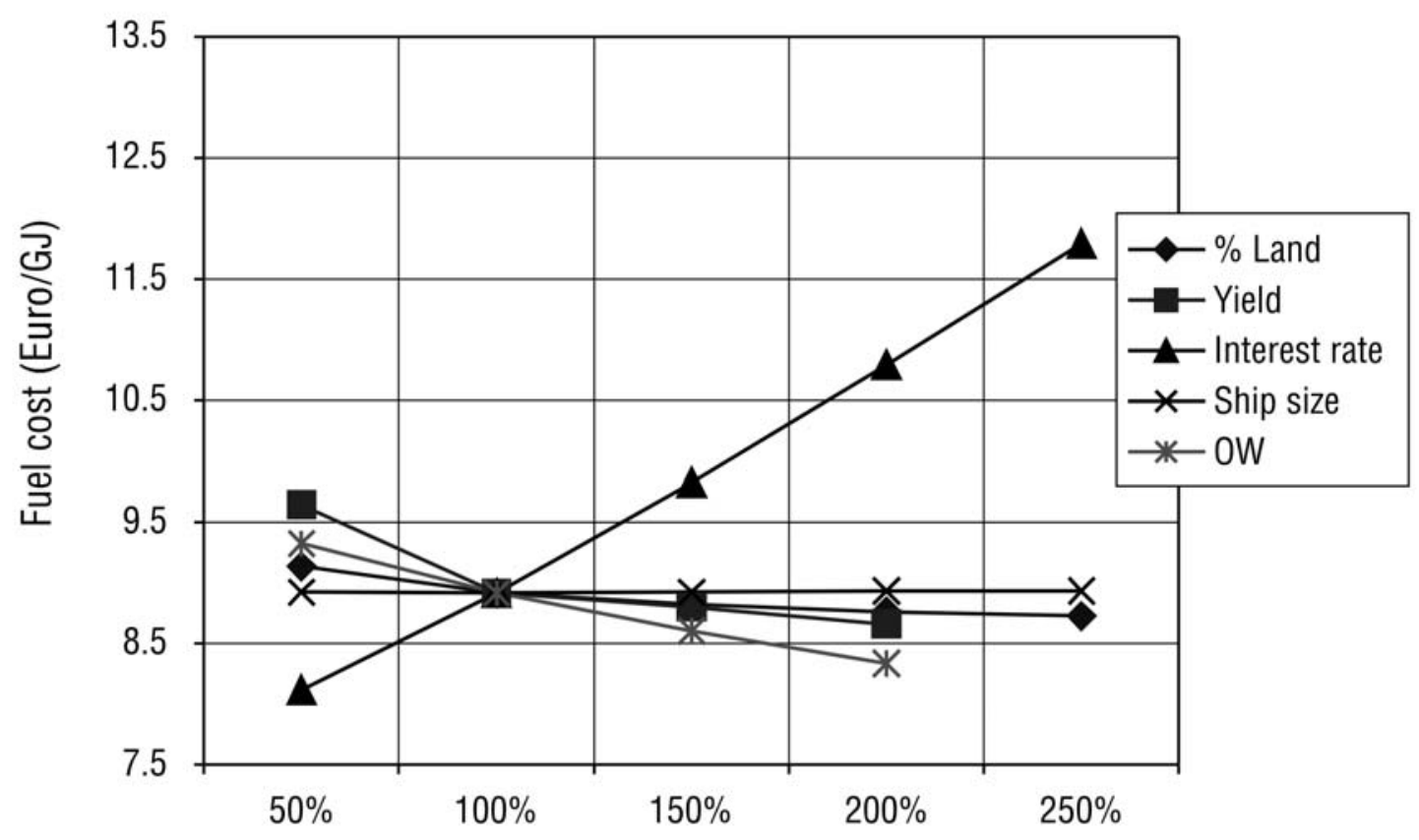

Parameter variation

Figure 19. Sensitivity analysis of FT fuel cost

pellets and pyrolysis oil are converted at the importing harbour (Rotterdam) and compared them with FT fuels supplied directly from Mozambique. Pellet conversion to FT fuel via EF gasification results in final fuel cost of 4.5 Euro/GJ while pyrolysis conversion gives fuel costing 4.8 Euro/GJ. This is much lower compared to the 6.8 Euro/GJ for FT produced centrally at source using CFB gasification (see Figure 21).

The primary energy requirement for energy (including losses and process inputs, see Note 26) is lowest for the EF pellet route $\left(2.93 \mathrm{GJ}_{\text {required }} / \mathrm{GJ}_{\text {delivered }}\right)$ and highest for the CFB route (5.24 $\left.\mathrm{GJ}_{\text {required }} / \mathrm{GJ}_{\text {delivered}}\right)$. The EF pyrolysis route requires $3.92 \mathrm{GJ}_{\text {required }} / \mathrm{GJ}_{\text {delivered. }}$ When comparing process energy inputs only, there are marginal differences in energy requirement for energy for the three supply chains averaging about $1.12 \mathrm{GJ}_{\text {primary }} / \mathrm{GJ}_{\text {delivered }}$.

In contrast, pellet chains have the highest $\mathrm{CO}_{2}$ emissions (5.3 $\left.\mathrm{kg} \mathrm{CO}_{2} / \mathrm{GJ}\right)$, pyrolysis $3.7 \mathrm{~kg} \mathrm{CO}_{2} / \mathrm{GJ}$ and $\mathrm{CFB}$ FT the least $\mathrm{CO}_{2}$ at $2.5 \mathrm{~kg} \mathrm{CO} / \mathrm{GJ}$.

The most attractive bioenergy logistic chain in terms of fuel cost and energy requirements is therefore FT synthesis from pellets while FT synthesis from pyrolysis is also highly competitive. The pellet chain however, has higher $\mathrm{CO}_{2}$ emission than the pyrolysis chain. FT production at source via CFB gasification performs the worst because of the high delivered fuel cost and high energy requirements, although it has low $\mathrm{CO}_{2}$ emissions.

\section{Conclusions and recommendations}

Mozambique has the potential to produce up to $6.7 \mathrm{EJ}$ annually of biomass energy using surplus land under mod- erate agricultural technological inputs. As expected, biomass production from arid regions is more costly than from productive regions. Production costs range from 0.6 to 1.2 Euro/GJ. However, biomass production costs have only a minor influence on final fuel costs; inland transport costs as well as pre-treatment costs are more decisive. This is shown by the higher fuel cost from Niassa where transport costs are very high, even though the region produces the lowest-cost biomass. The mountainous regions are generally used for forestry plantations and are a natural choice for energy plantations. This makes the sparselypopulated and humid region of Niassa very suitable for intensive energy crop production.

The study has shown that early conversion of biomass to either pellets or pyrolysis at local facilities reduces overall logistic costs, indicating that truck transportation of raw biomass is much more important in the overall costs than the benefits of economies of scale achieved at centralised facilities. The opposite is true for FischerTropsch conversion where large-scale production results in fuel cost reductions of up to $24 \%$.

Pellets are delivered at a cheaper cost $(2.6$ Euro/GJ) than pyrolysis (3.2 Euro/GJ) or FT fuels (6.8 Euro/GJ). This shows that the higher transportation costs due to higher volumes of pellets are more than compensated by the high conversion cost for FT fuels (2.2 Euro/GJ) and higher handling costs for pyrolysis oil.

Conversion of pellets and pyrolysis to FT fuels via EF gasification at the importing harbour results in fuel costs of 4.5 and 4.8 Euro/GJ compared to 6.8 Euro/GJ for FT fuels produced centrally at source using CFB gasification. 


\section{Articles}

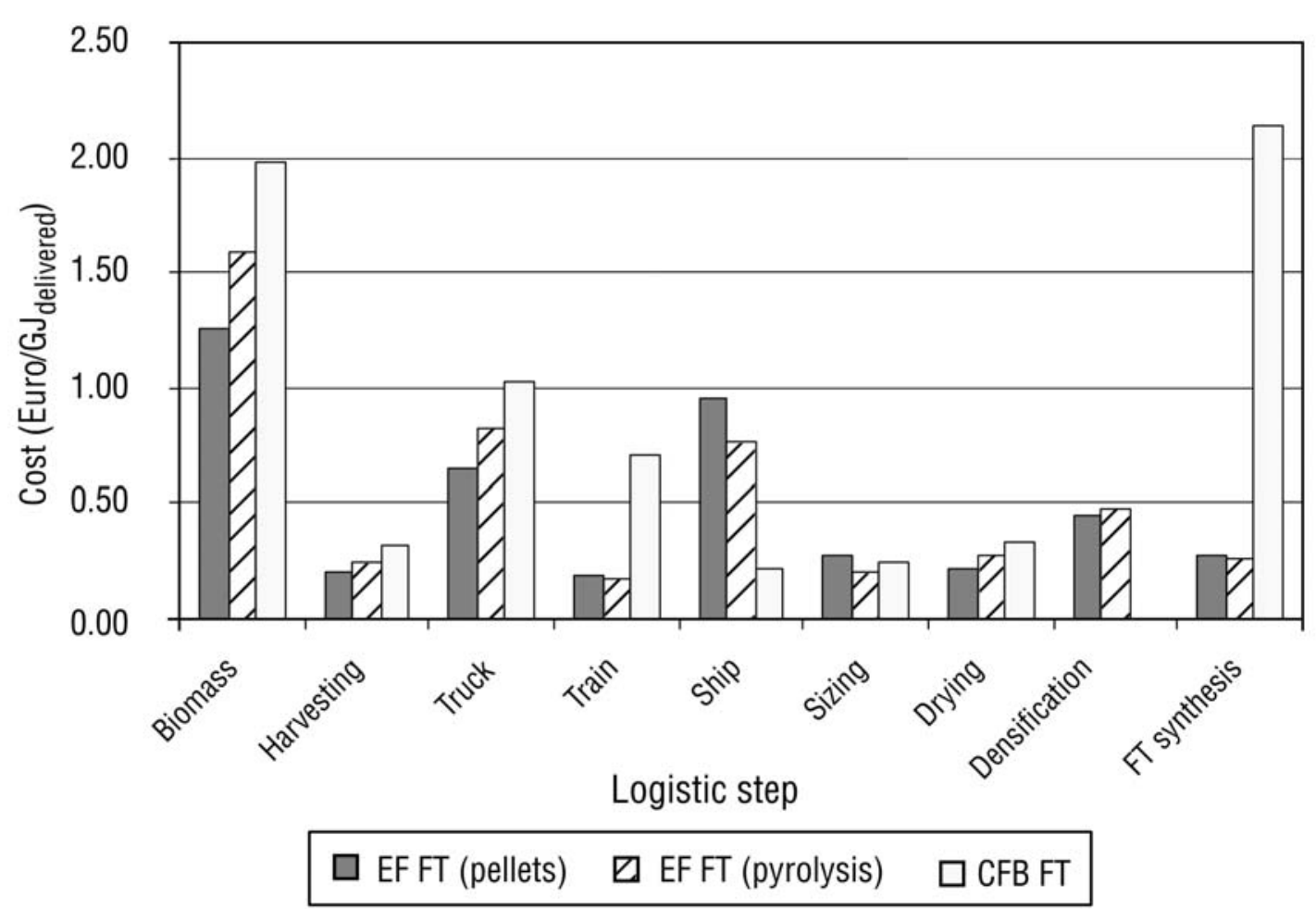

Figure 20. Comparison of FT costs via 3 routes (EF of pellets or pyrolysis oil vs CFB)

The most attractive supply chain in terms of delivered fuel cost and energy requirements was found to be the local conversion of biomass to pellets with further conversion to FT fuels using entrained flow gasification. In terms of $\mathrm{CO}_{2}$ emissions, the pyrolysis chain is the most attractive. Centralised production of FT fuels via CFB gasification performs the worst when compared to the other two routes.

Mozambique is strategically positioned to exploit its potential to produce biomass energy for export to the international market as well as meet some of its own internal energy needs. In line with the Mozambican government's agricultural and economic development policies, sustainable cultivation of energy crops has the potential to open up rural areas, creating employment, improving degraded land and infrastructure while generating much-needed foreign currency. It is therefore important for Mozambique to utilise marginal, abandoned and uninhabited areas where competition with food production and ecosystem preservation is not critical.

The highly productive mountainous regions of Niassa, Manica and Tete are especially suited for energy cropgrowing while posing no threat to food production. Long transport distances raise logistic costs for these regions but early conversion to liquid fuels in the supply chain ensures that the final delivered fuel is competitive. For the arid regions where biomass production costs may be high due to low productivities, opportunities still exist to use marginal land which may not be under crop production. This study has shown that delivered fuel cost from arid regions may still be competitive where appropriate infrastructure is available. However, investors have to take into account the risks of longer rotation and possible drought and fires in the arid areas.

Sofala offers the most cost-efficient production and delivery sites of biomass fuels because of its proximity to the coast and developed rail infrastructure. This is unlike other coastal areas which are without rail infrastructure or sea-going ports. Sofala also has many districts that are sparsely populated, enabling large-scale commercial farming without conflicts between villagers and farmers. Nevertheless, small-scale growers among local communities can also contribute to energy farming, thereby diversifying and enhancing their sources of income.

For maximum biomass productivity, selection of species should be in accordance with site conditions because of the diverse environmental conditions prevailing in the country. Other crops such as perennial grasses can also be grown although there is no experience in Africa of large-scale commercial production of such crops. Other important sources of biomass include natural forest-logging residues and timber-processing waste. If a market is developed for these waste products, timber companies may have incentives to collect and process the waste into biomass fuels. This may also discourage the uneconomic export of low-value raw logs and promote the expansion of the wood-processing industry.

While the best logistics of supplying bioenergy from Mozambique have been found to be local production of pellets and pyrolysis in the Sofala region and eventual conversion to FT fuels in Rotterdam, this is largely because local synthesis of FT fuels will demand large amounts of biomass feedstock, which may not be achievable 


\section{Articles}

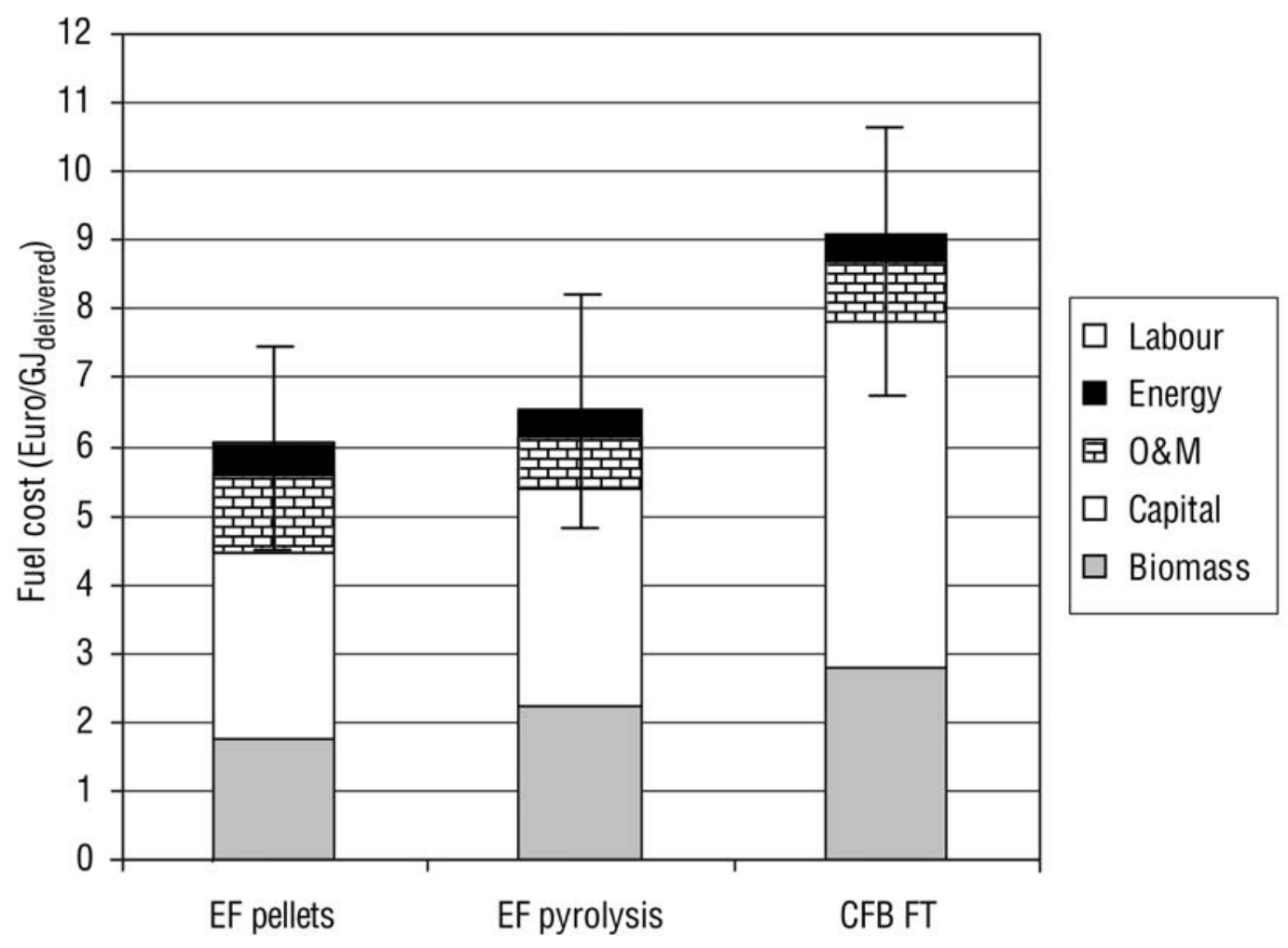

Figure 21. Range of costs for FT fuel delivered at Rotterdam harbour

in the short term. However, in the long term, it may be possible to establish large-scale FT fuel synthesis plants in Mozambique which may be supplied by biomass from one or several regions. This will require improvement in infrastructure, especially rail. In addition, more experience, technical know-how and biomass production capacity will need developing in the country. For the short to medium term, pellets are recommended as an intermediate biofuel for international trade because the delivered fuel cost is cheaper and energy losses are lower than for either pyrolysis oil or FT fuel (produced at source).

It may be necessary to conduct risk assessment studies to assist in potential investment decision-making. Support may also be necessary in further research in developing energy crops that maximise yields for selected regions and further reducing the investment and operational cost of conversion technologies. It is also important to assess the likely ecological and socio-economic impacts of bioenergy production.

This study is indicative of the potential role of biomass fuel production from Sub-Saharan Africa. It provides an overview of the resources in Mozambique and production potential therefrom. By comparing the various technologies and production regions, it establishes the conditions and critical factors for a successful bioenergy programme in Mozambique. This should set the basis for further analysis for investment and policy-making.

\section{Notes}

1. Since 1996, real GDP growth has averaged $10 \%$ per annum in a non-inflationary environment. Real per capita GDP growth has been about $7.5 \%$ per annum [UNDP, 2000 , p. 3].
2. Agricultural land combines arable (cultivated) land, permanent crops and permanent pasture.

3. The livestock sector in Mozambique is small (estimated cattle herd was about 200,000) and contributes less than $1 \%$ to total agricultural production. Cattle production is limited to fly-free areas (25\% of the country) and generally livestock production is pastoral and undertaken by the family sector, although there is growing commercial sector activity [Da Silva et al., 1995]. The dividing line between "permanent pasture" and "forests and woodland" is rather indefinite, especially in the case of shrubs, savannah, etc., which may have been reported under either of these two categories [FAO, 2003a].

4. EFI [2003] estimates area under timber plantations to be about 45,500 ha. These were formerly government plantations established to provide alternative source of fuelwood for urban areas. Most of them have been privatised and the only major commercial plantation (about 25,000 ha under pine and eucalyptus) is under IFLOMA Industries in Manica province. Government withdrawal has been necessitated by a poor market for eucalyptus wood products [Cruz, 2004], poor project planning [Mangue, 2000] and general divestiture by the state under market reforms.

5. The term "level of technology" refers to the use of fertilizers, pesticides, mechanised tools, improved breeds, double-cropping, and the application of irrigation, and is used interchangeably with any or all of these conditions throughout this paper.

6. The "feed conversion efficiency" is production in $\mathrm{kg}$ of animal product per $\mathrm{kg}$ feed (i.e., what is displayed in Table 5 is strictly the reciprocal of this parameter).

7. Less than $3 \%$ of the farmers use chemical fertilizers and less than $5 \%$ use pesticides (exceptions are cotton-growers), only $11 \%$ use animal traction for cultivation and less than $4 \%$ of the farmers use irrigation [INE, 2001]. Mozambique's agricultural sector is going through rapid transition. Its post-independence centrally-planned economy favoured heavy investment in state farms, but changes in policy and liberalisation have led to the state withdrawing from public enterprises [Mucavale, 2000; Wils, 2002]. The last decade has seen a move away from a centrally-planned state management, pricing and marketing of agriculture, towards a more market liberalized allocation of agricultural resources, pricing policies and privatisation of state assets. The focus of agricultural policies is on stimulating increased production to ensure food security and increase exportable cash crops, and adding value to agricultural produce through the development of agro-industries [NDC, 2003].

8. Mozambique is a large country with diverse physiographic, geological and climatic conditions which make regional classification a complex task. 10 agro-ecological zones (AEZs) have been identified but are difficult to use with the administrative geographical boundaries. A more generalised approach which uses the so-called food economy zones (FEZs) was used in this study as defined by Bias and Donovan [2003]. FEZs roughly 


\section{Articles}

correspond to AEZs but they have the advantage that they relate to specific districts with defined hectarage, and are therefore easier to interpret and use than AEZs.

9. Total primary energy demand in Mozambique is about $300 \mathrm{PJ}$ of which wood-fuel accounts for $87 \%$, hydroelectricity represents $8 \%$ and $5 \%$ is fossil fuel [WRI, 2004].

10. As discussed in Section 3, preference in land allocation is given to food production with the most productive land being reserved for food crops, implying there is generally no competition for marginal land.

11. The highest sustainable production potential is found in Sofala province (yield of 0.043 $\mathrm{m}^{3} / \mathrm{ha} / \mathrm{yr}$ ) while the least is found in Maputo province (with $0.007 \mathrm{~m}^{3} / \mathrm{ha} / \mathrm{yr}$ ) [EFI, 2003; Fath, 2002; NDC, 2004].

12. About $16 \mathrm{Mm}^{3}$ of woody biomass is also used for $80 \%$ of household energy needs per year [Oreste and Cuamba, 1998; EFI, 2003].

13. Based on the Zimbabwean ethanol and sugar production plant with capacity of $1.9 \mathrm{Mt}$ of cane per year, and producing $200,000 \mathrm{t}$ of sugar and $40 \mathrm{Ml}$ of ethanol [Hall et al., 1991].

14. Studies in Maputo indicate that weeds significantly affected the early development of E. camaldulensis [Macucule, 2001].

15. Labour costs are reportedly very dynamic due to the transition taking place in Mozambique [Cruz, 2004]. In the long term, labour costs are likely to stabilise towards average Sub-Saharan rates which are still very low compared to average global rates. A survey conducted by Nasir et al. [2001] indicates average unskilled worker wages in Mozambique of about $\$ 43$ a month, well below other African countries e.g., Madagascar (\$55-65) and Nigeria (\$87)

16. In the arid regions, soils cannot sustain plantation densities beyond 2500 trees/ha, but it is possible to increase tree densities beyond $2 \times 2 \mathrm{~m}$ in more productive soils [Cruz, 2004]. Planting density also affects the rate at which the tree canopy closes, weed competition, the growth form of the trees, and the maximum tree size. Narrow spacings minimize weed problems by closing the canopy within the first year. Wider spacings require weed control for 2-3 years until trees are 1.5-2 m tall and the canopy closes [Perlack et al., 1997].

17. E. camaldulensis is widely regarded as the most suitable species for many regions of Mozambique, especially the semi-arid zones [Macucule, 2001]. Plantation yields show great variation and depend mostly on site productive capacity, site matching/species selection, stocking of the stands and silvicultural treatments. Some species exhibit tolerance to drought, flooding, salinity, calcareous soils, and cold. E. camaldulensis is well known for its suitability to poor tropical sites, whereas $E$. grandis and $E$. saligna have best growth and survival records in humid climates [Vichnevetskaia, 1997; Pandey, 1987].

18. Broek [2000] estimates eucalyptus production costs (including logistics up to the mill and $25 \%$ profit margin) at 1.7 Euro/GJ for Nicaragua; biomass yields in this case were estimated to be $12.7 \mathrm{tdm} / \mathrm{ha} / \mathrm{yr}$.

19. For a discussion on how to estimate first transport distance, see [Dam, 2004].

20. The operating window is the time period during the year during which operations are carried out, therefore impacting on the utilisation of equipment and investment costs.

21. An example of feller buncher used in this study is the Frobbesta harvester (capacity of $53 \mathrm{~m}^{3}$ bulk per hour, costs of about 75,000 Euro including tractor) [WSRG, 2004] Chain-saws $\left(110 \mathrm{~cm}^{3}\right)$ for manual-motor felling cost around $\$ 800$ [Fath, 2002].

22. Moisture content requirements are $8-12 \%$ for pelletising, $7 \%$ for pyrolysis and $10-15 \%$ for CFB gasification.

23. Average investment costs for $\mathrm{FT}$ fuel production using pyrolysis oil as feedstock via $\mathrm{EF}$ gasification are much cheaper $\left(140,000\right.$ Euro/MW $\left.W_{\text {th,in }}\right)$ than direct gasification of chips because of the easier fuel feed and conversion of oil to gas, unlike gasification of solid fuel. The higher pyrolysis conversion investment costs are compensated by the lowe gasification, transportation and syngas conditioning costs. Direct gasification of chips is the more costly (0.23-0.44 M Euro/MW th,in) despite lower downstream logistic costs. If pulverised pellets are used as feedstock with $\mathrm{EF}$ gasification, average investment costs are about $0.16 \mathrm{M}$ Euro/MW $/ \mathrm{W}_{\text {th, in }}$

According to a study conducted by Calis et al. [2003], investment in a pressurised oxygen-blown CFB gasifier (operating at 20 bar) ranges from 120 to 310 Euro/kW including fuel-feeding, cracker and syngas cooler. The higher end represents maximum investment cost for plant capacities of $200 \mathrm{MW}_{\text {th }}$ while the lower end is for capacities of $1000 \mathrm{MW}_{\text {th. }}$ A scale factor of 0.6 is used in this case.

Investment cost for atmospheric systems ranges from 245 to 330 Euro/ $\mathrm{MW}_{\text {th }}$ for 85 $\mathrm{MW}_{\text {th }}$ plant capacity. On the other hand $\mathrm{EF}$ gasifier investment (including fuel-feeding and syngas cooler) ranges from about 41 to $75 \mathrm{Euro} / \mathrm{kW}_{\text {th }}$ with pyrolysis oil as feed for capacities of $1000 \mathrm{MW}_{\text {th }}$ and $300 \mathrm{MW}_{\text {th }}$ respectively. If solid biomass is used with an EF gasifier, investment costs increase to $45 \mathrm{Euro} / \mathrm{kW}_{\text {th }}$ for $1000 \mathrm{MW}_{\text {th }}$ capacity.

24. Using a capacity of $150,000 \mathrm{t}$ ( $150 \mathrm{kt}$ ) per ship, a fleet of 5 bulk carriers, for example, can make 9 trips to cover pellet supply from each region. Each ship carries cargo (deadweight) of $95 \%$ for tankers and $85 \%$ for dry cargo. [Hamelinck et al., 2003].

25. We used a normalised biomass output from each region of $131 \mathrm{PJ}$ per annum to enable fair comparison between regions.
26. Energy requirement for energy is an indication of the amount of primary energy required for a chain of processes leading to the supply of one unit of energy (end-use). By calculating how much energy goes into each energy conversion process in the chain (taking into account the conversion efficiencies), one estimates the total amount of primary energy required to supply a certain amount of final energy.

27. Logistic capacity is the total volume of biofuels being handled by the logistic facility (truck, storage, etc.)

28. For the sensitivity analysis, the following parameter variations were used: percentage of land under energy crops $(5 \% \rightarrow 25 \%$ of total land area); interest rates $(5 \% \rightarrow$ $25 \%$ ); ship sizes $(100 \rightarrow 200 \mathrm{kt})$; biomass yields $(15 \rightarrow 35 \mathrm{t} \mathrm{dm} / \mathrm{ha} / \mathrm{yr})$; operating windows ( $6 \rightarrow 12$ months).

29. Pyrolysis oil is corrosive and requires special steel-lined holding tanks which increase tanker costs by up to $14 \%$ [Hamelinck et al., 2003]

\section{References}

African Development Bank (AfDB), 1995. Country Environmental Profile: Mozambique, Environmental and Social Policy Working Paper Series, Working Paper No. 21, African Development Bank, Tunis, Tunisia.

Banco de Moçambique (BdM), 2005. http://www.bancomoc.mz.

Bias, C., and Donovan, C., 2003. Gaps and Opportunities for Agricultural Sector Development in Mozambique, Research Report No. 54E, Ministry of Agriculture and Rural Development, Mozambique.

Broek, R. van den, 2000. Sustainability of Biomass Electricity Systems. An Assessment of Costs, Macro-economic and Environmental Impacts in Nicaragua, Ireland and the Netherlands, Eburon Delft.

Calis, H.P., Haan, J.P., Peppink, G., Boerigter, H., Drift, B. van der, Venderbosch, R.J., Faaij, A.P.C., and Broek, R. van den, 2003. Technical and Economic Feasibility of Large-scale Synthesis Gas Production in the Netherlands from Imported Biomass Feedstock - a Strategic Decision Analysis Study, pp. 50.

Coelho, J.-P.B., and Littlejohn, G.M., 2000. El Nino 1997-1998. The Case of the 1997-98 El Nino. Mozambique Case Study. Reducing the Impact of Environmental Emergencies Through Early Warning and Preparedness, UNEP/NCAR/UNU/WMO/ISDR.

Centro de Promoção de Investimentos (Investment Promotion Centre)-Mozambique (CPI), 2005. Cost Factors in Mozambique, http://www.cpi.co.mz.

Cruz, E., (National Directorate for Forestry and Wildlife), 2004. Personal communication. Da Silva, M.A.C., Alves, T., Tember, J., and Munisse, P., 1995. Mozambique: Country Report to the FAO International Technical Conference on Plant Genetic Resources (Leipzig, 1996), Maputo.

Dam, J. van, 2004. Possibilities and Performance of International Biofuel Trade from CEEC to WEC, VIEWLS project, Utrecht University, Utrecht, the Netherlands.

De Quadros, M.C., 2003. "Current land policy issues in Mozambique", in Groppo, P., (ed.), Land Reform: Land Settlement and Cooperatives, Special Edition, FAO/World Bank.

Deepchand, K., 2001. Bagasse Based Cogeneration in Mauritius - A Model for Eastern and Southern Africa, AFREPREN Occassional Paper No. 2, Nairobi.

European Forest Institute (EFI), 2003. Country Reports - Mozambique, Certification Information Service, http://www.efi.fi.cis/english/creports/mozambique.php.

Faaij, A.P.C., 2004. "International bio-energy trade; background, opportunities and IEA Task 40", Proceedings of the Second International Ukrainian Conference on Biomass for Energy, Kiev, Ukraine, 20-22 September, Insitute of Engineering Thermophysics, National Academy of Sciences Scientific Engineering Centre, "Biomass", p. 4.

Food and Agriculture Organisation (FAO), 2002. Global Agro-ecological Assessment for Agriculture in the 21st Century: Methodology and Results, Food and Agriculture Organisation, Rome, Italy.

Food and Agriculture Organisation (FAO), 2003a. FAO Stat Database - Agricultural Data, http://apps.fao.org/page/collections, Food Agriculture Organisation, Rome, Italy.

Food and Agriculture Organisation (FAO), 2003b. World Agriculture: Towards 2015/2030. An FAO Perspective, Food Agriculture Organisation and Earthscan Publications Ltd., London, UK.

Food and Agriculture Organisation/Global Information and Early Warning System (FAO/GIEWS), 2005. Workstation-Mozambique Country Profile, http://www.fao.org/giews/.

Fath, H., 2002. Commercial Timber Harvesting in the Natural Forests of Mozambique. Forest Harvesting Case Study, Food and Agriculture Organisation, No. 18, Rome.

Hall, D.O., Scurlock, J., and Rosenschein, A. 1991. Fuelling the Future. Power Alcohol in Zimbabwe, ACTS Press, Nairobi.

Hamelinck, C., Suurs, R.A.A., and Faaij, A.P.C., 2003. International Bioenergy Transport Costs and Energy Balance, Utrecht University, Utrecht, the Netherlands.

Hamelinck, C., 2004. Outlook for Advanced Biofuels, Utrecht University, Utrecht, the Netherlands.

Hoogwijk, M., 2004. On the Global and Regional Potential of Renewable Energy Sources, 


\section{Articles}

Ph.D. thesis, Utrecht University, Utrecht, the Netherlands.

IMAGE-team, 2001. The IMAGE 2.2 Implementation of the SRES Scenarios: a Comprehensive Analysis of Emissions, Climate Change and Impacts in the 21st Century, Bilthoven, the Netherlands, National Institute for Public Health and the Environment.

Instituto Nacional de Estatística (INE), 2001. Agricultural Census: 1999-2000. Summary of the Results, Maputo.

Instituto Nacional de Estatística (INE), 2004. Second General Population and Housing Census, 1997, Maputo.

Jeje, J.J., Machungo, C., Howard, J., Strasberg, P., Tschirley, D., Crawford, E., and Weber, M., 1998. What Makes Agricultural Intensification Profitable for Mozambican Smallholders? An Appraisal of the Inputs Subsector and the 1996/97 DNER/SG2000 Program. Volume II: Main Report, Research Report No. 32.

Junginger, M., Faaij, A., Broek, R. van den, Koopmans, A., and Hulscher, W., 2001. "Fuel supply strategies for large scale bio-energy projects in developing countries. Electricity generation from agricultural and forest residues in Northeastern Thailand", Biomass and Bioenergy, Vol. 21, pp. 259-275, Elsevier Science.

Kwesha, D., and Matarira, C.H. 2004. GHG Offsets Potential (Agriculture And Forestry), Climate Change Office, Zimbabwe.

Laclau, J.-P., Delaporte, P., Ranger, J., Bouillet, J.-P., and Kazotti, G., 2003. "Nutrient dynamics throughout the rotation of eucalyptus clonal stands in Congo", Annals of Botany, 91, pp. 879-892.

Lingen, S. van der, (Wattle Company), 2004. Personal communication. Zimbabwe.

Locke, A., 2003. "The Mozambique sugar industry: overview and outlook", Proceedings of The FAO/Mozabique Sugar Conference. Sugar and Development in Africa and The World: Sustainability, Diversification and Trade, Maputo, Mozambique, 10-12 October, Food and Agriculture Organisation, Rome.

Mabvurira, D., and Pukkala, T., 2002. "Optimising the management of Eucalyptus grandis (hill) maiden plantations in Zimbabwe", Forest Ecology and Management, 166, pp. 149-157, Elsevier Science.

Macucule, A., (ed.), 2001. Resumos dos Trabalhos de Licenciatura, Abstracts of Theses: 1990-2001, Departamento de Engenharia Florestal, Faculdade de Agronomia e Engenharia Florestal, Universidade Eduardo Mondlane, Projecto FAO - GCP/Moz/056/Net, Maputo.

Mangue, P.D., 2000. Review of the Exisiting Studies Related to Fuelwood and Charcoal in Mozambique. EC-FAO Partnership Programme (1998-2002), EC DGVIII/FAO/AfDB, Maputo. Marrison, C.I., and Larson, E.D., 1996. "A preliminary analysis of the biomass energy production potential in Africa in 2025 considering projected land needs for food production", Biomass and Bioenergy, Vol. 10, Nos. 5/6, pp. 337-351.

Maya, R.S., Nziramasanga, N.P., Muguti, E., and Fenhann, J., 1993. UNEP Greenhouse Gas Abatement Costing Studies. Zimbabwe Country Study. Phase II, Southern Centre for Energy and Environment/Riso National Laboratory/Department of Energy (Zimbabwe).

Ministry of Mines, Environment and Tourism - Zimbabwe (MMETZ), 1998. Zimbabwe's Initial Communication on Climate Change, Harare.

Moyo, S., O'Keefe, P., and Sill, M., 1993. The Southern African Environment. Profile of the $S A D C$ Countries, Earthscan Publications, London.

Mucavele, F.G., 2000. Analysis of Comparative Advantage and Agricultural Trade in Mozambique, Eduardo Mondlane University, Technical Paper No. 107, SD Publication Series, USAID, Office of Sustainable Development, Bureau for Africa, November.
Nakicenovic, N., and Swart, R., (eds.), 2000. IPCC Special Report on Emissions Scenarios, Cambridge University Press, Cambridge, UK, 599 pp.

Nacala Development Corridor (NDC), 2003. The Transport Logistics and Infrastructure Framework. Economic Sector Development Perspectives.

Nacala Development Corridor (NDC), 2004. http://www.nacalacorridor.com/English/projects/ Nasir, J., de Baros, G., Wagle, D., Kediah Shah, M., Leechor, C., Srivastava, P., Harding, A., and Ramachandran, V., 2003. Pilot Investment Climate Assessment, Mozambique Industrial Performance and Investment Climate 2003, Regional Program on Enterprise Development, Africa Private Sector Group, The World Bank/IFC, August.

Nhantumbo, I., 2000. "The new resource tenure framework in Mozambique: does it really give the tenancy to the rural communities?", paper prepared for the 8th Biennial Conference of the International Association for the Study of Common Property (IASCP), 31 May-3 June.

Oreste Nacala, M., and Cuemba, C.C., 1998. "Forest Data for Mozambique", Proceedings of Sub-regional Workshop on Forestry Statistics SADC Region, Mutare, Zimbabwe, 30 November-4 December, Data Collection and Analysis for Sustainable Forest Management in ACP Countries - Linking National and International Efforts, EC-FAO Partnership Programme (1998-2000).

Pandey, D., 1987. "A Unasylva technical note: yield model of plantations in the tropics", Unasylva, Vol. 39, No. 157-158, Small-scale Forest Enterprises, Food and Agriculture Organisation, Rome.

Perlack, R.D., Wright, L.L., and Huston, M., 1997. Biomass Fuel from Woody Crops for Electric Power, Winrock International, USA.

Reyes, D., 2003. An Evaluation of Commercial Logging in Mozambique. Corporate Options: Constructive Engagement in Conflict Zones, Collaboration for Development Action.

Rossiter, D.G., 1994. Land Evaluation, Cornell University,

http://www.itc.nl/ rossiter/pubs/s494toc.htm

Smeets, E., Faaij, A.P.C., and Lewandowski, I., 2004. A Quickscan of Global Bio-energy Potentials to 2050. Bottom-Up Scenario Analysis of Regional Biomass Production and Export Potentials, Fair Biotrade Project, Utrecht University.

Smeets, E.M.W., Faaij, A.P.C., Lewandowski, I.M., and Turkenburg, W.C., 2005. "A quickscan of global bio-energy potentials to 2050", submitted for publication in Progress in Energy and Combustion Science, October.

Ugalde, L., and Perez, O., 2001. Mean Annual Volume Increment of Selected Industrial Forest Plantation Species, Forest Plantation Thematic Papers, Food and Agriculture Organisation, Rome.

United Nations Development Programme (UNDP), 2000. Mozambique Common Country Assessment. UN System in Mozambique, Maputo.

United Nations Development Programme (UNDP), 2003. World Population Prospects. The 2002 Revision - Highlights, United Nations Population Division, New York, USA.

Vichnevetskaia, K., 1997. Factors Affecting Productivity of Tropical Forest Plantations: Acacia, Eucalypt, Teak, Pine, Working Paper GFSS/WP/02, Food and Agriculture Organisation, Rome.

Wils, A., 2002. Population-Development-Environment in Mozambique. Background Readings, International Institute for Applied System Analysis, Laxenburg, Austria. World Resources Institute (WRI), 2003. Country Profiles - Mozambique, http://earthtrends.wri.org

Wood Supply Research Group (WSRG), 2004. The Coppice Harvesting Decision Support System, University of Aberdeen.

\section{Contributions invited}

Energy for Sustainable Development is a venture in the field of journals on energy with a special focus on the problems of developing countries. It attempts a balanced treatment of renewable sources of energy, improvements in the efficiency of energy production and consumption, and energy planning, including the hardware and software (policy) required to translate interesting and useful new developments into action.

With such a multi-disciplinary approach, Energy for Sustainable Development addresses itself to both specialist workers in energy and related fields, and decision-makers. It endeavours to maintain high academic standards without losing sight of the relevance of its content to the problems of developing countries and to practical programmes of action. It tries to provide a forum for the exchange of information, including practical experience.

Articles and short articles published are subject to a formal process of peer review.

Material for publication may be e-mailed to the Technical Editor, Gautam Dutt, at gdutt@fibertel.com.ar.

For guidelines to authors on the preparation of the text and other material, see Page 2. 